\author{
Contato \\ University of Saint Andrews - School of Classics \\ Swallowgate - Butts Wynd \\ Fife KY16 9AL - Saint Andrews - Escócia \\ carm3@st-andrews.ac.uk
}

\section{A ANTIGUIDADE TARDIA, A QUEDA DO IMPÉRIO ROMANO E O DEBATE SOBRE O "FIM DO MUNDO ANTIGO"**}

Carlos Augusto Ribeiro Machado*

University of Saint Andrews

Fife - Escócia - Reino Unido

\title{
Resumo
}

A Antiguidade tardia está hoje consolidada seja como campo de estudos ou como um período histórico. No entanto, desde sua concepção até a sua "explosão", para usarmos uma expressão de Andrea Giardina, esta periodização colocou questões historiográficas de imensa importância que permanecem pouco exploradas. Ao chamar a atenção de estudiosos e leitores em geral para as continuidades entre o mundo antigo e o período que o seguiu, a Antiguidade tardia deixa de lado importantes questões que eram fundamentais para uma historiografia mais tradicional e que continuam relevantes, como o problema da assim chamada queda do Império romano. Neste artigo, pretendemos discutir estas questões, levando em considerações os importantes desenvolvimentos observados nas últimas décadas.

\section{Palavras-chave}

Antiguidade tardia - Império romano - historiografia.

* Este artigo foi redigido enquanto fui professor de História Antiga da Universidade de São Paulo e é um produto das discussões e das trocas de ideias que travei com diversos amigos e colegas. Gostaria de agradecer, assim, as sugestões e críticas de Fábio Morales, Uiran Gebara da Silva, Norberto Guarinello e Miguel Palmeira. Gostaria de agradecer especialmente à Fundação de Amparo à Pesquisa do Estado de São Paulo (Fapesp) pelo apoio imprescindível para a redação deste trabalho através de um auxílio regular à pesquisa recebido durante este período.

${ }^{* *}$ Formado em História pela Universidade Federal Fluminense, mestre em História Econômica pela Universidade de São Paulo e doutor em História Antiga pela Universidade de Oxford, Inglaterra. Professor (lecturer) de História Antiga na School of Classics da Universidade de Saint Andrews, Escócia. Diretor do Centro de Estudos sobre a Antiguidade Tardia da Universidade de Saint Andrews. 


\author{
Contact \\ University of Saint Andrews - School of Classics \\ Swallowgate - Butts Wynd \\ Fife KY16 9AL - Saint Andrews - Escócia \\ carm3@st-andrews.ac.uk
}

\section{LATE ANTIQUITY, THE FALL OF ROME AND THE DEBATE OVER THE "END OF THE ANCIENT WORLD"}

\section{Carlos Augusto Ribeiro Machado}

University of Saint Andrews

Fife - Scotland - United Kingdom

\begin{abstract}
Late Antiquity is now consolidated both as a field of studies and as a historical period. However, from the time of its inception to its "explosion", to use an expression of Andrea Giardina, this periodization has posed important historiographic questions that remain unexplored. By focusing the attention of scholars and students in general on the continuities between the ancient world and the period that follow it, Late Antiquity leaves aside issues that were of crucial importance to traditional historians; some of these issues remain relevant, however, as in the case of the so-called fall of the Roman Empire. In this article, we intend to consider these issues, taking into account the important developments observed in recent decades.
\end{abstract}

\title{
Keywords
}

Late Antiquity - Roman Empire - historiography. 
rev. hist. (São Paulo), n. 173, p. 81-114, jul.-dez., 2015 http://dx.doi.org/10.11606/issn.2316-9141.rh.2015.105844
Carlos Augusto Ribeiro Machado

A Antiguidade tardia, a queda do Império romano e o debate sobre o "fim do mundo antigo"

Um espectro ronda a história da Antiguidade tardia: a queda do Império romano. O fato de que o evento político por definição, que por séculos atraiu a atenção de historiadores (além de filósofos e teólogos), tenha se tornado, nos últimos anos, um grande incômodo, é algo surpreendente e que merece nossa atenção. Quando Arnaldo Momigliano escreveu, em 1959, a introdução para a série de conferências que ele havia organizado no Instituto Warburg de Londres um ano antes, ele ainda podia abrir sua exposição observando: "ainda é possível considerar uma verdade histórica o fato de que o Império romano declinou e caiu" (grifos meus). ${ }^{1}$ Em pouco mais de uma década, no entanto, Momigliano assistiria à implosão desse consenso, à negação dessa verdade histórica e à redução desse fato, até então de proporções épicas, a uma mera data nas cronologias que normalmente fecham os livros sobre esse período - isso quando o próprio fato não era negado.

A segunda metade do século XX foi marcada por uma profunda reavaliação desse período histórico que chamamos de Antiguidade tardia, normalmente identificado como se estendendo do final do século III ao final do século VII. Essa reavaliação pode ser caracterizada como uma verdadeira revolução historiográfica, não apenas em termos das novas fontes, dos novos métodos e das novas abordagens adotados, mas até mesmo em termos de como o período é entendido por seus estudiosos. Como observou Andrea Giardina, nenhum período histórico na Antiguidade é visto atualmente de forma tão positiva e otimista quanto os seus últimos séculos. ${ }^{2}$ A despeito disso, o início do século XXI foi marcado pelo aparecimento de livros com títulos bombásticos como "A queda do Império romano", de Peter Heather, e "A queda de Roma e o fim da civilização", de Bryan Ward-Perkins, respectivamente, e à eclosão de um debate que em momentos extrapola a academia, assumindo conotações políticas e um tom de troca de críticas pessoais entre estudiosos. ${ }^{3}$

Excessos retóricos à parte, o problema da queda do Império romano e do fim do mundo antigo retornou ao centro do debate sobre como podemos

\footnotetext{
1 MOMIGLIANO, A. El cristianismo y la decadencia del Imperio romano. In: MOMIGLIANO, A. (org.). El conflicto entre el paganismo y el cristianismo en el siglo IV. Madri: Alianza Editorial, 1989, p. 15.

2 GIARDINA, Andrea. Esplosione di tardoantico. Studi Storici. Roma, n. 40, 1999, p. 162.

3 HEATHER, P. The fall of the Roman Empire. Londres: MacMillan, 2005; e WARD-PERKINS, B. The fall of Rome and the end of civilization. Oxford: Oxford University Press, 2005. Os livros foram resenhados por James O'Donnell, por exemplo, que chamou os autores de "neo-cons". Disponível em: http://bmcr.brynmawr.edu/2005/2005-07-69.html. Para um exemplo da repercussão política deste debate ver Illegal immigration led to the fall of the Roman Empire. The Conservative Papers, 22 janeiro 2012. Disponível em: http://conservativepapers.com/news/2012/01/22/illegal-immigration-led-to-the-fall-of-the-roman-empire/\#.UeRFw41BXHQ. Acesso a ambos em: 15/07/2013.
} 
definir e caracterizar a Antiguidade tardia, e faz-se necessário discuti-lo aqui. É preciso considerar este debate em sua historicidade, buscando identificar os termos nos quais ele foi colocado. Como chegamos a ele, e por que ele é tão central para nossa definição do que são a história antiga e a história medieval? De que forma as novas abordagens desenvolvidas nas últimas décadas levaram a ele? Qual o papel de nossas fontes em seu desenvolvimento e na definição de seus contornos? É possível incorporar a problemática da "queda do Império" às novas abordagens sobre o período?

O objetivo deste artigo é discutir essas questões como forma de explorar os limites e as contribuições dessa periodização. Inicialmente, pretendo explorar alguns aspectos da gênese da ideia de Antiguidade tardia. ${ }^{4}$ A partir daí, discutirei as implicações deste conceito para nossa periodização da história antiga, assim como seu impacto na própria maneira como definimos geograficamente esse espaço-tempo. Isso terá implicações diretas na forma como dois conceitos-chave, "transição" e "crise", são utilizados ou (mais frequentemente) negados pelos historiadores, e eu pretendo discutir essa questão colocando ênfase especialmente na problemática das "invasões bárbaras". Essa é a base para minha discussão final, na qual pretendo tomar o caso da historiografia sobre as cidades e a vida cívica como fio condutor para discutir o problema de como continuidades e rupturas se combinam para fazer desse período algo específico, mas ao mesmo tempo parte de uma unidade cronológica mais ampla, a Antiguidade. Obviamente, nenhuma destas questões poderá ser respondida de forma definitiva, mas pretendo ao menos apresentar alguns dos debates historiográficos mais importantes, explicitando as bases sobre as quais os historiadores têm trabalhado nos últimos anos.

\section{Um conceito e suas origens}

O conceito moderno de Antiguidade tardia tem suas origens na obra do historiador da arte Alois Riegl, especialmente em Die Spätantike Kunstindustrie, de 1901. Nesta obra, Riegl observou que, longe de ser decadente, a arte do período era produto de um gosto artístico diferente que, na verdade, poderia ser comparado aos movimentos artísticos de finais do século XIX e início do XX, livres do peso do classicismo. A arte do final da

\footnotetext{
${ }_{4}$ A melhor discussão da gênese do conceito é a de BROWN, P. et alii. The world of late Antiquity revisited. Symbolae Osloenses. Oslo, n. 72, 1997, p. 5-90. Para uma pré-história do conceito, ver ELSNER, J. The birth of late Antiquity: Riegl and Strzygowski in 1901. Art History. Londres, n. 25, 2002, p. 358-379.
} 
rev. hist. (São Paulo), n. 173, p. 81-114, jul.-dez., 2015 http://dx.doi.org/10.11606/issn.2316-9141.rh.2015.105844
Carlos Augusto Ribeiro Machado

A Antiguidade tardia, a queda do Império romano e o debate sobre o "fim do mundo antigo"

Antiguidade podia, assim, ser associada à arte moderna, por seu potencial de inovação e liberdade estilística. ${ }^{5}$ A identificação da Antiguidade tardia como uma época autônoma na história da Antiguidade ganhou peso na primeira metade do século XX, como se pode observar na obra de Santo Mazzarino. ${ }^{6}$ Para Mazzarino, o período deveria ser entendido em sua especificidade com um ordenamento político e social próprios, retirando a centralidade da ideia de decadência. A importância dessa nova atitude também foi percebida por Henri-Irenée Marrou, cujo livro sobre santo Agostinho e a cultura de seu tempo foi revisto após sua primeira edição com uma Retractatio (empregando o vocabulário de sua fonte) na qual Marrou reconhecia o valor e a originalidade da época do bispo de Hipona. ${ }^{7}$

Pode-se dizer, no entanto, que foi The world of late Antiquity: from Marcus Aurelius to Muhammad (estranhamente traduzido para o português como $O$ fim do mundo clássico - o que contradiz a essência do livro), de Peter Brown, que definiu os contornos e a perspectiva como a historiografia posterior veio a enxergar a Antiguidade tardia. ${ }^{8}$ O livro é parte de uma coleção dedicada à história ilustrada da Europa, dirigida por Geoffrey Barraclough - que escolheu o título e a designação do período a ser tratado. Anos mais tarde, Brown observou que não havia lido a obra de Riegl, mas que o título proposto se adequava ao que ele pensava. ${ }^{9}$ O livro trata do período que se estende do reinado de Marco Aurélio (161-180) ao século posterior à ascensão do Islã (a última data citada é 800 d. C.). Ao mesmo tempo em que reconhece impor-

\footnotetext{
5 Para uma discussão da análise de Riegl e seu impacto entre historiadores da arte, ver ELSNER, J., 2002, op. cit., p. 361-370. Para a importância historiográfica de Riegl e seu conceito, ver, de forma mais ampla, GIARDINA, Andrea. Esplosione di tardoantico. Studi Storici. Roma, n. 40, 1999 , p. 157-160. Foi R. Bianchi Bandinelli o primeiro a observar que o termo Spätantike/Antiguidade tardia derivava da obra de Riegl: BIANCHI BANDINELLI, R. Spaetantike. In: Enciclopedia dell'Arte Antica, vol. 7. Roma: Treccani, 1966, p. 426-427. Disponível em: http://www.treccani.it/ enciclopedia/spaetantike_(Enciclopedia-dell'-Arte-Antica)/. Acesso em: 15/07/2013.

${ }^{6}$ MAZZARINO, S. Stilicone: La crise imperiale dopo Teodosio. Milão: Rizzoli, 1942 e MAZZARINO, S. Aspetti sociali del quarto secolo: ricerche di storia tardo-romana. Roma: L'Erma di Bretschneider, 1951. O autor deu continuidade a estes estudos em duas obras fundamentais: MAZZARINO, S. O fim do mundo antigo. São Paulo: Martins Fontes, 1988 (originalmente publicado em 1959) e nos artigos reunidos em Antico, tardoantico ed èra costantiniana, 2 vol. Bari: Edizioni Dedalo, 1974.

7 MARROU, H.-I. Saint Augustine et la fin de la culture antique. Paris: E. De Boccard, 1949.

8 BROWN, P. The world of late Antiquity: from Marcus Aurelius to Muhammad. Londres: Thames and Hudson, 1971. A edição portuguesa foi publicada pela editora Verbo, em 1972. Para o contexto de produção intelectual e o impacto da obra, ver BROWN, P. et alii. The world of late Antiquity revisited. Symbolae Osloenses. Oslo, n. 72, 1997, p. 5-90.

9 BROWN, P. et alii. The world of late Antiquity revisited. Symbolae Osloenses. Oslo, n. 72, 1997, p. 17.
} 
tantes mudanças sociais e políticas, Brown enfatiza o notável grau de continuidade e vitalidade culturais. De certa forma, as teses de Henri Pirenne em Maomé e Carlos Magno foram retomadas, ainda que de forma modificada. ${ }^{10}$

É importante ressaltar que esta concepção de Antiguidade tardia, positiva e baseada na ênfase nas continuidades, não implicou no abandono de visões tradicionais sobre o período, preocupadas com o problema do "declínio de Roma". Podemos dizer mais: a revolução historiográfica promovida por Brown não teria sido possível sem a publicação, em 1964, do monumental The later Roman Empire, de A. H. M. Jones, uma obra que - como o subtítulo nos informa - oferecia um survey das instituições políticas, econômicas e sociais do Império, e que ainda hoje permanece referência obrigatória para todos os estudiosos do período. ${ }^{11}$ Jones sistematizou toda a informação disponível à época (especialmente através de fontes literárias e epigráficas de diversas naturezas) em capítulos temáticos que servem como verdadeiros guias e pontos de partida para estudiosos de temas tão diversos como o governo, o exército e as finanças, entre outros. A publicação do LRE, como é comumente chamado, colocou o estudo do período em novas bases, não só pela quantidade de informações e fontes que reuniu, mas também pela sua análise judiciosa e por suas interpretações inovadoras. Foi, como observou o próprio Brown em uma resenha famosa, "como a chegada de uma usina siderúrgica em uma região que havia sido, até há pouco, entregue a indústrias leves". ${ }^{12}$ Para o que nos interessa, a obra de Jones foi importante por ter liberado os historiadores para explorar novos temas, tomando como pano de fundo um baixo império mais diverso, dinâmico e fluido do que aquele com o qual seus predecessores haviam lidado. Partindo de novas bases, e influenciados por desenvolvimentos no estudo de outros períodos históricos e em disciplinas como a antropologia, tornou-se então possível estudar questões ligadas à história da cultura e das religiões de uma nova forma.

\footnotetext{
${ }^{10}$ Como o próprio Brown notou: BROWN, P. et alii. The world of late Antiquity revisited. Symbolae Osloenses. Oslo, n. 72, 1997, p. 16-17. Brown discutiu a importância da obra de Pirenne e seus problemas em um número especial da revista Daedalus, de 1974: BROWN, P. Mohammed and Charlemagne by Henri Pirenne. In: Idem. Society and the holy in late Antiquity. Berkeley: University of California Press, 1982, p. 63-79.

${ }^{11}$ JONES, A. H. M. The later Roman Empire 284-602. A social, economic and administrative survey, 3 vol. Oxford: Basil Blackwell, 1964. Para uma reavaliação da obra e seu impacto, veja os artigos reunidos em GWYNN, D. (org.). A. H. M. Jones and the later Roman Empire. Leiden: Brill, 2008.

${ }^{12}$ BROWN, P. The later Roman Empire. In: Idem. Religion and society in the age of Augustine of Hippo. Nova York: Harper \& Row, 1972, p. 49.
} 


\section{Um espaço-tempo? Problemas de periodização e localização}

A Antiguidade tardia descrita por Brown em livros influentes teve enorme impacto entre os historiadores, levando à consolidação de um campo intelectual específico, com pesquisadores próprios, posições em departamentos de prestígio, coleções de livros e jornais especializados. O problema, como observaram diversos críticos, é que os diversos textos programáticos publicados pelo próprio Brown e seus colegas colocam mais dificuldades do que as resolvem. ${ }^{13}$

Uma primeira questão que se coloca é: seria a Antiguidade tardia um período histórico específico? Desde Gibbon, historiadores sempre tiveram dificuldades em definir cronologicamente o que seria o fim da Antiguidade. A primeira edição da Cambridge Ancient history, publicada entre 1924 e 1939, concluía com Constantino, mas deixava a fundação de Constantinopla para a Cambridge Medieval history. Nem mesmo o mais empedernido historiador da política insistiria hoje na deposição do último imperador do Ocidente, o jovem Rômulo, em 476, como um limite cronológico adequado - foi uma "queda sem ruído", como observou Momigliano. ${ }^{14} \mathrm{O}$ já citado Pirenne enfatizara as continuidades entre a época de Constantino e o período merovíngio, no que foi seguido por dois arqueólogos, Richard Hodges e David Whitehouse, em um livro de 1983. ${ }^{15}$ Alguns anos depois, Andrea Carandini sugeriu que o mundo antigo acabara no século II d. C. e que a Europa medieval não nascera da "raiz viva do Império, mas do seu parque arqueológico".16 Mais

\footnotetext{
${ }_{13}$ Para um texto de forte caráter de manifesto, ver BOWERSOCK, Glen; BROWN, Peter; GRABAR, André. Introduction. In: BOWERSOCK, Glen; BROWN, Peter; GRABAR, André (org.). Late Antiquity. A guide to the postclassical world. Cambridge, MA: Harvard University Press, 1999, p. vii-xiii. Ver também CAMERON, Averil. The Mediterranean world in late Antiquity. Londres: Routledge, 1995, e, de forma mais explícita, CAMERON, Averil. Ideologies and agendas in late antique studies. In: LAVAN, Luke $\&$ BOWDEN, Will (org.). Theory and practice in late antique archaeology (Late antique archaeology 1). Leiden: Brill, 2003, p. 3-21. MARROU, Henri-Irenée. Décadence romaine or Antiquité tardive? IIIe - VIe siècle. Paris: Éditions du Seuil, 1977, cita Brown apenas uma vez (p. 111) e deve ser considerado o produto de um desenvolvimento independente, apesar de muito próximo.

${ }^{14}$ MOMIGLIANO, Arnaldo. La caduta senza rumore di un Impero nel 476. In: Idem. Sesto contributo alla storia degli studi classici e del mondo antico. Roma: Edizioni di Storia e Letteratura, 1980, p. 159-165. JONES, A. H. M. The later Roman Empire 284-602. A social, economic and administrative survey, 3 vols. Oxford: Basil Blackwell, 1964, p. V, justifica sua escolha do final do reino de Mauricio (602) como marco cronológico baseado no que ele identificou como declínio irreversível do Oriente e o quase desaparecimento de fontes contemporâneas.

${ }^{15}$ Em WHITEHOUSE, David \& HODGES, Richard. Mohammed, Charlemagne and the origins of Europe. Ithaca: Cornell University Press, 1983.

${ }^{16}$ CARANDINI, Andrea. L'ultima civiltà sepolta o del massimo oggetto desueto, secondo un archeologo. In: CARANDINI, Andrea; CRACCO RUGGINI, Lellia; GIARDINA, Andrea (org.).
} 
rev. hist. (São Paulo), n. 173, p. 81-114, jul.-dez., 2015 http://dx.doi.org/10.11606/issn.2316-9141.rh.2015.105844
Carlos Augusto Ribeiro Machado

A Antiguidade tardia, a queda do Império romano e o debate sobre o "fim do mundo antigo"

ou menos na mesma época, outro arqueólogo, Klavs Randsborg, sugeriu o oposto: apesar de reconhecer que mudanças importantes ocorreram, como o surgimento de novos centros manufatureiros e o desenvolvimento de novas periferias, Randsborg argumentou que a cultura material mudou pouco até cerca do ano 1000, defendendo a necessidade de se adotar uma cronologia muito mais ampla. ${ }^{17}$ Se estou citando prioritariamente as obras de arqueólogos é porque mesmo historiadores concordam que as antigas periodizações baseadas em "grandes datas" não são satisfatórias, e a arqueologia tem desempenhado um papel crucial em nossa compreensão da história social e cultural do período.

Historiadores como Peter Brown e Averil Cameron advogam a ideia de uma "longa Antiguidade tardia" que se estenderia do século II ao VIII. Não é coincidência que os dois autores trabalhem principalmente com o Mediterrâneo oriental, onde as continuidades são efetivamente mais representativas. Seja porque menos afetadas por invasões e guerras civis ou graças a sua maior pujança econômica, as províncias orientais do Império demonstram grande vitalidade tanto na vida rural (como no caso das aldeias camponesas da Síria) quanto urbana, até pelo menos o final do século VI e o início do VII, quando a peste e as guerras bizantino-persas e, mais tarde, a expansão do Islã representaram uma ruptura mais séria. ${ }^{18}$ Esse é um argumento frequentemente utilizado por autores que rejeitam a ideia de "crise" como prova de que ela não existiu. ${ }^{19}$ Todavia, nem mesmo a continuidade institucional do Império bizantino deve obscurecer o fato de que o Império sob Justiniano (527-565) era muito diferente do Império sob o primeiro imperador iconoclasta, Leão III, o Isáurio. O problema, no entanto, não reside na existência ou não de uma crise do Mediterrâneo oriental (isto é incontroverso), mas,

Storia di Roma, vol. 3: L'età tardoantica, tomo 2: I luoghi e le culture. Turim: Einaudi, 1993, p. 16.

${ }^{17}$ RANDSBORG, Klavs. The first millenium A. D. in Europe and the Mediterranean: An archaeological essay. Cambridge: Cambridge University Press, 1991. Ver também RANDSBORG, Klavs. Barbarians, classical Antiquity, and the rise of Western Europe: An archaeological essay. Past and Present. Oxford, n. 137, 1991, p. 8-24.

${ }^{18}$ Como argumenta WHITTOW, Mark. Decline and fall? Studying long term change in the East. In: LAVAN, Luke $\&$ BOWDEN, Will (org.). Theory and practice in late antique archaeology (Late antique archaeology 1). Leiden: Brill, 2003, p. 404-423. Ver também WHITTOW, Mark. The making of orthodox byzantium, 600-1025. Basingstoke: Palgrave, 1996, p. 69-95. Para uma visão mais nuançada, ver HALDON, John. Social transformation in the 6th-9th c. East. In: BOWDEN, Will; GUTTERIDGE, Adam; MACHADO, Carlos (org.). Social and political life in late Antiquity (Late antique archaeology 3.1). Leiden: Brill, 2006, p. 603-647.

${ }^{19}$ Ver a resenha de O'Donnell, sobre os livros de Ward-Perkins e Heather, citada acima. 
sim, de seus tempos e ritmos. Podemos assim perguntar: até que ponto uma "crise", caracterizada por diversos processos e elementos comuns, precisa ser observável ao mesmo tempo e do mesmo modo em todos os lugares para ser reconhecida como "geral"?

A redefinição geográfica da área a ser estudada é, de fato, outro aspecto crucial no modo como o período é definido: o foco dos historiadores se concentra na Ásia menor e na Síria (atualmente cada vez mais no Egito), mas a lente se amplia para incorporar regiões como o Irã e a Irlanda. Norberto Guarinello discutiu, alguns anos atrás, aquilo que ele caracterizou como a "forma" da história antiga (ou as formas, no plural), o modo como enquadramos nossas narrativas e objetos de estudo de modo a dar-lhes coerência e sentido - no caso, tomando o mundo mediterrâneo, grosso modo, entre os séculos VIII a. C. e V d. C., como uma unidade concreta, um pano de fundo e ponto de referência. ${ }^{20}$ Nesse sentido, é importante enfatizar a ruptura na qual a ideia de Antiguidade tardia implica: trata-se de uma forma que não corresponde à forma história antiga, quanto mais ao Império romano. Peter Brown percebera isso, ao afirmar que se poderia falar de um budismo tardo-antigo, mas não tardo-romano. ${ }^{21}$ Mais recentemente, ele voltou a esse problema ao discutir um grupo de livros dedicados a regiões decididamente não romanas, mas que mantiveram contatos com o antigo Império: o Iêmen, a Etiópia e a Ásia central. Incorporar as transformações políticas e religiosas destas áreas é crucial para uma compreensão mais sofisticada e adequada da história do período. ${ }^{22}$ É inegável que processos como a descolonização da Ásia e da África, a crítica ao orientalismo e a uma visão eurocêntrica do mundo exerceram um papel importante nessa abertura. Por outro lado, o desenvolvimento da arqueologia, da epigrafia e do conhecimento de línguas não clássicas me parece ter exercido um papel ainda mais preponderante neste processo. Afinal, tiveram árabes, etíopes e irlandeses uma Antiguidade clássica? Essa não é uma pergunta ociosa, e voltaremos a ela mais abaixo, quando estivermos tratando das controvérsias que marcam o estudo desse período.

\footnotetext{
${ }^{20}$ GUARINELLO, Norberto. Uma morfologia da história: As formas da história antiga. Politeia: História e Sociedade. Vitória da Conquista, 2003, v. 3, p. 41-61.

${ }^{21}$ BROWN, P. et alii. The world of late Antiquity revisited. Symbolae Osloenses. Oslo, 1997, n. 72, p. 17-18.

${ }^{22}$ Em Recovering submerged worlds. The New York Review of Books, 11 julho 2013. Disponível em: http://www.nybooks.com/articles/archives/2013/jul/11/recovering-submerged-worlds/. Acesso em: 16/07/2013.
} 


\section{“Transição", "crise" e o problema das "invasões bárbaras"}

No momento, o que precisamos considerar é o fato de que a definição cronológica e geográfica do "mundo da Antiguidade tardia" coloca um problema mais complicado, o de como podemos definir este período. Como observou Giardina, defini-lo como uma época de transição e, ao mesmo tempo, um período autônomo que deve ser tomado em seus próprios termos é, antes de mais nada, uma contradição. ${ }^{23}$ Ele sugere - e aqui sua proximidade com as ideias de Carandini e do grupo de estudiosos marxistas ligados ao Instituto Gramsci nos anos 1980 é clara - que a transição ocorreu entre o reinado de Marco Aurélio e o de Diocleciano, ou seja, durante um período de aproximadamente 120 anos. $^{24}$

Segundo essa escola interpretativa, a crise do modo de produção escravista e a formação de latifundia na Itália (que já existiam em algumas províncias), paralelamente à fragilização do campesinato, levaram à progressiva adoção de uma mão-de-obra agrícola que era juridicamente livre, porém presa ao solo - o colonato. Essa nova instituição foi consolidada através de uma série de leis promulgadas por Constantino e preservadas no Código Teodosiano. ${ }^{25}$ A introdução do solidus por Constantino levou a um enorme abismo social entre aqueles que podiam utilizar a nova moeda e aqueles que foram relegados às denominações menores, marcando o futuro das populações camponesas. ${ }^{26}$ Paralelamente a essas transformações sociais, a crise da economia italiana (e a interpretação desta escola é essencialmente centrada no caso da Itália) - decorrente da competição provincial - foi associada à crise geral do mundo romano no século III, um período caracterizado por problemas políticos (especialmente relativos à sucessão imperial), mas principalmente por guerras (civis e contra invasores) e a peste. Estes não são

\footnotetext{
${ }^{25}$ GIARDINA, A. Esplosione di tardoantico. Studi Storici. Roma, 1999, n. 40, p. 162.

${ }^{24}$ GIARDINA, Andrea. The transition to late Antiquity. In: SCHEIDEL, Walter; MORRIS, Ian; SALLER, Richard (org.). The Cambridge economic history of the Greco-Roman world. Cambridge: Cambridge University Press, 2007, p. 743-768.

${ }^{25}$ GIARDINA, Andrea, op. cit., 2007, p. 748-752.

${ }^{26}$ GIARDINA, Andrea, op. cit., 2007, p. 760. Ver, sobre o solidus, também as observações de BANAJI, Jairus. Agrarian change in late Antiquity. Oxford: Oxford University Press, 2001, p. 36-37. Para o lugar da moeda constantiniana no sistema monetário tardo-antigo, ver agora CARLÀ, Filippo. Il sistema monetario in età tardoantica: spunti per una revisione. Annali dell'Istituto Italiano di Numismatica. Roma, n. 53, 2007, p. 155-218.
} 
rev. hist. (São Paulo), n. 173, p. 81-114, jul.-dez., 2015 http://dx.doi.org/10.11606/issn.2316-9141.rh.2015.105844
Carlos Augusto Ribeiro Machado

A Antiguidade tardia, a queda do Império romano e o debate sobre o "fim do mundo antigo"

processos idênticos, mas que foram combinados e que levaram à formação de uma nova sociedade e ordenamento políticos.

Note-se que a caracterização de Giardina não tem nada de esquemático e, em nenhum momento, ele sugere que qualquer um desses processos fosse inevitável. O que fica claro, aqui, é que a sociedade que emergiu das transformações ocorridas entre o final do século II e o final do III era profundamente diferente daquela da época dos Antoninos. "Crise”, aqui, é entendida como um processo de transformação das estruturas sociais fundamentais, e o próprio Giardina observa que, na terminologia marxista, tanto "crise" quanto "transição" podem levar a uma fase de expansão econômica, ao invés de caos e declínio. ${ }^{27}$

Deve-se salientar que existem aspectos controversos na argumentação de Giardina, especialmente na sua interpretação da legislação sobre o colonato como um elemento central na nova formação social. ${ }^{28}$ Ao invés de criticarem a interpretação de Giardina, no entanto, a imensa maioria dos historiadores contemporâneos simplesmente renuncia à noção de "crise", observando em primeiro lugar que seus indícios não podem ser generalizados, e, em segundo lugar, denunciando-a como um juízo de valor negativo. ${ }^{29}$ Em última análise, no entanto, o que permitiu aos tardo-antiquistas ignorar a noção de "crise" e o uso de estruturas englobantes, como Estado e sociedade, foi o desenvolvimento de novas perspectivas históricas e, especialmente, o impacto de correntes filosóficas pós-modernas. Isso pode ser visto no caso de estudos sobre temas novos como a memória, por Michael Maas, ${ }^{30}$ e mes-

\footnotetext{
${ }^{27}$ GIARDINA, Andrea. Marxism and historiography: Perspectives on Roman history. In: WICKHAM, Chris (org.) Marxist history-writing for the twenty-first century (British Academy Occasional Paper 9). Oxford: Oxford University Press, 2007, p. 27.

${ }^{28}$ CARRIÉ, Jean-Michel. Le "colonat" du bas-Empire: un mythe historiographique? Opus. Roma, 1982, n. 1, p. 351-371. GREY, Cam. Contextualizing colonatus: the Origo of the late Roman Empire. Journal of Roman Studies. Londres, 2007, n. 97, p. 155-175. Para uma crítica recente à teoria do colonato e suas implicações, ver SILVA, Uiran G. Bagaudas e circunceliões: revoltas rurais e a escrita da história das classes subalternas na Antiguidade tardia. Tese de doutoramento, USP, 2013, p. 24-27.

${ }^{29}$ Como defende WITSCHEL, Christian. Re-evaluating the Roman West in the $3^{\text {rd }}$ century. Journal of Roman Archaeology. Portsmouth, n. 17, 2004, p. 273. Witschel realiza um extenso levantamento da evidência disponível para o século III em todo o Ocidente romano, argumentando que não se pode falar de um processo unificado de transformação. Para uma crítica do conceito de crise que o reduz a um juízo de valor, ver CARRIÉ, Jean-Michel \& ROUSSELLE, Aline. L'Empire romain en mutation. Paris: Seuil, 1999, p. 90-91.

${ }^{30}$ MAAS, Michael. John Lydus and the Roman past. Londres: Routledge, 1992.
} 
mo na análise de temas tradicionais como as relações entre igreja e estado no século IV, por Neil McLynn. ${ }^{31}$

No caso da obra de Maas sobre João, o Lídio, um burocrata e antiquário que no século VI escreveu uma obra crucial sobre as magistraturas romanas (especialmente a prefeitura do pretório), o texto é tomado como um produto cultural de seu tempo e não como uma descrição histórica das realidades do governo romano e do declínio de um de seus departamentos mais importantes. Assim, o que se privilegia é o modo como o passado é construído e apropriado, deixando de lado o conteúdo factual da obra: segundo Maas, o autor bizantino criou uma teoria do poder imperial romano a partir da qual ele julgava o governo de Justiniano. ${ }^{32}$ Apesar de fazer uma sutil análise sobre as relações entre igreja e estado (e religião e política) na Milão de finais do século IV, o estudo de McLynn sobre Ambrósio, bispo de Milão, é muito mais interessado nas formas como estas relações são culturalmente construídas e manipuladas, e especialmente nas estratégias de autorrepresentação adotadas pelo bispo milanês.

É importante salientar que tanto o livro de Maas quanto o de McLynn são reconhecidamente inovadores e fundamentais para os temas que eles estudam, e se eu os cito aqui é precisamente porque eles mostram o quanto estas novas perspectivas têm a nos ensinar sobre o período e sociedades em questão. Lidando com temas próximos destes autores, Gilvan Ventura da Silva se beneficiou do avanço destas novas correntes interpretativas em seu estudo sobre o reinado de Constâncio II (337-361). Concentrando-se em um reinado específico, o autor faz uso da antropologia social e, especialmente, dos estudos sobre a magia, para analisar não só os termos em que o poder imperial se legitimava, mas também os seus limites e modos de atuação, contribuindo enormemente para uma visão mais sofisticada da política nesse período. ${ }^{33}$

O risco está em se adotar perspectivas a-históricas, algo que aparece de forma clara no livro de Christopher Kelly, Ruling the later Roman Empire, de 2004; apesar de tratar do tema mais tradicional possível, o governo, o autor o faz de maneira inovadora, incorporando elementos da antropologia cultural e política e desfazendo as fronteiras entre Estado e sociedade. Longe do

\footnotetext{
${ }^{31}$ MCLYNN, Neil. Ambrose of Milan: Church and court in a Christian capital. Berkeley: University of California Press, 1994.

${ }^{32}$ MAAS, Michael. John Lydus and the Roman past. Londres: Routledge, 1992, p. 72.

33 SILVA, Gilvan Ventura da. Reis, santos e feiticeiros. Constâncio II e os fundamentos místicos da Basileia, 337-361. Vitória: Edufes, 2003.
} 
formalismo e do institucionalismo tradicionais, que encontramos na obra de Jones, por exemplo, o que encontramos no livro de Kelly é uma estimulante discussão de como o acesso ao poder imperial e aos seus departamentos era uma forma de exercer e adquirir poder na sociedade tardo-imperial. ${ }^{34}$ Isso lhe permite não só criticar a noção de que a corrupção do governo levou à queda do Império romano, ${ }^{35}$ mas mostrar que o pagamento por serviços e a troca de favores eram um elemento estruturante na forma como o poder era exercido naquela sociedade. Por outro lado, a análise de Kelly apresenta o Estado imperial como algo praticamente imutável de Diocleciano a Justiniano - isso em uma época para a qual a mudança parece ter sido a maior constante, especialmente em termos da abrangência geográfica e da capacidade de se financiar deste Estado.

O problema pode ser colocado da seguinte forma: por um lado, as novas abordagens "tardo-antiquistas" trouxeram grandes avanços para nossa compreensão das sociedades que estudamos, mostrando que, se houve uma crise, esta não abarcou todos os aspectos da vida dos contemporâneos e se manifestou em tempos e lugares diferentes. Por outro lado, se decidirmos considerar a Antiguidade tardia como um período a ser entendido em seus próprios termos, precisamos também esclarecer quais foram os processos históricos que permitiram que esse período fosse diferente do que o precedeu - e nesse caso simplesmente apontar continuidades como um meio de negar a crise não basta. Ou seja, estamos falando de uma época "em si", de uma época "de transição", ou de uma fase específica da história antiga, diferente, mas marcada pela continuidade?

O impacto do linguistic turn e da história e antropologia culturais não se faz sentir apenas no modo como definimos a Antiguidade tardia qua período histórico, mas também na maneira como avaliamos os elementos que a caracterizam. Isso pode ser apreciado - tanto em seus aspectos positivos quanto negativos - na discussão contemporânea sobre as outrora chamadas "invasões bárbaras". ${ }^{6}$ Enquanto para um historiador como André Piganiol restavam poucas dúvidas de que Roma fora assassinada pelos invasores germânicos, ${ }^{37}$ o debate atual é muito mais sofisticado e frequentemente coloca-

\footnotetext{
${ }^{34}$ KELLY, Christopher. Ruling the later Roman Empire. Cambridge, MA: Harvard University Press, 2004.

35 Uma tese explicitamente afirmada na obra de MacMULLEN, Ramsay. Corruption and the decline of Rome. New Haven: Yale University Press, 1988.

${ }^{36}$ Para uma avaliação equilibrada das questões que seguem, ver GASPARRI, Stefano \& LA ROCCA, Cristina. Tempibarbarici. L'Europa occidentale tra Antichità e Medioevo (300-800). Roma: Carocci, 2012, p. 63-92.

37 Parafraseando PIGANIOL, André. L'empire chrétien. Paris: Presses Universitaires de France, 1947, p. 466.
} 
rev. hist. (São Paulo), n. 173, p. 81-114, jul.-dez., 2015 http://dx.doi.org/10.11606/issn.2316-9141.rh.2015.105844
Carlos Augusto Ribeiro Machado

A Antiguidade tardia, a queda do Império romano e o debate sobre o "fim do mundo antigo"

do em termos que teriam feito um historiador francês da primeira metade do século XX se assustar (o que não é necessariamente ruim!). Até a metade do século XX, as invasões eram descritas como "ondas", representadas graficamente por flechas coloridas identificando os diversos grupos germânicos que penetraram o Império. Gustaf Kossinna havia demonstrado como a arqueologia podia identificar as culturas materiais dos grupos étnicos descritos pelos autores romanos, e os historiadores podiam se utilizar de textos como as cartas e os comentários de Jerônimo a Daniel, Isaías e Ezequiel, compostos entre 407 e 410, para enriquecer sua narrativa como Pierre Courcelle o havia feito. ${ }^{38}$

Essa visão foi vigorosamente criticada nos últimos anos por estudiosos como Walter Pohl, Florin Curta e Patrick Geary. Curta faz uso do conceito de etnogênese para demonstrar que é impossível identificar grupos étnicos a partir da cultura material. "Romanos", "francos", "vândalos" e "alanos" são categorias construídas e constantemente redefinidas, em parte por autores (e autoridades imperiais) romanos e em parte pelos grupos que eles descrevem. Etnias são construções socioculturais, estratégias de identificação e distinção que permanecem abertas e cambiantes. ${ }^{39}$ Pohl, por sua vez, observou de maneira contundente a inaplicabilidade das "etnografias" produzidas por autores romanos no estudo dos "povos bárbaros", indo mais além e enfatizando a profunda integração entre romanos e outros povos. ${ }^{40}$ Patrick Geary incorporou outra variável, política, a essa problemática, observando que os líderes dos grupos que se estabeleceram em áreas imperiais logo eram cooptados pelo jogo político das autoridades e da corte, às vezes com consequências catastróficas como no caso dos godos nos Bálcãs, em 375. Aí, a incompreensão das elites romanas lidando com um grupo assentado, porém ainda armado, levou à derrota imperial em Adrianopolis em 378. Mais tarde, esse mesmo grupo formou os visigodos que, liderados por Alarico - um líder frequentemente envolvido em políticas imperiais -, tomaram Roma em 410

${ }^{38}$ COURCELLE, Pierre. Histoire littéraire des grandes invasions germaniques. Paris: Hachette, 1948, p. 29. Para Kossinna, ver CURTA, Florin. Some remarks on ethnicity in medieval archaeology. Early Medieval Europe. Londres, n. 15, 2007, p. 160-161.

39 CURTA, Florin, op. cit., 2007, p. 160-161; ver também GASPARRI, Stefano \& LA ROCCA, Cristina. Tempi barbarici. L'Europa occidentale tra Antichità e Medioevo (300-800). Roma: Carocci, 2012, p. 83-88.

${ }^{40}$ POHL, Walter. Romans and the Barbarians in the fifth century. Antiquité Tardive. Turnhout, n. 16, 2008, p. 93-100. O uso de etnografias antigas como chave para o estudo de grupos não romanos foi objeto de críticas de JONES, Sian. The archaeology of ethnicity. Londres: Routledge, 1997, e, mais recentemente, de WOOLF, Greg. Tales of the Barbarians. Oxford: Blackwell, 2011. 
rev. hist. (São Paulo), n. 173, p. 81-114, jul.-dez., 2015 http://dx.doi.org/10.11606/issn.2316-9141.rh.2015.105844
Carlos Augusto Ribeiro Machado

A Antiguidade tardia, a queda do Império romano e o debate sobre o "fim do mundo antigo"

e saquearam o sul da Itália até se assentarem na Gália na década seguinte. ${ }^{41}$ É interessante observar que, no caso desses três autores, os "bárbaros" que antes eram vistos como elementos externos e destruidores do mundo antigo se tornaram um objeto de estudo central para nossa compreensão da Antiguidade tardia, o que pode ser visto como uma consequência indireta daquela ampliação do foco dos historiadores de que falamos acima.

Arqueólogos como Philipp von Rummel e Paul Van Ossel têm chamado a atenção para o quanto é problemático associar invasões bárbaras a assentamentos pobres e sinais de destruição. Von Rummel mostrou que não existem traços arqueológicos de destruição causada pelos vândalos no norte da África, apesar dos relatos catastróficos que encontramos em um sermão de Quodvultdeus (De tempore barbarico II, 5.5), por exemplo. ${ }^{42}$ Van Ossel tem demonstrado que os assentamentos muito pobres do norte da Gália, tradicionalmente identificados como bárbaros, são mais provavelmente aldeias camponesas, confirmando o caráter invisível das populações invasoras - ao menos no registro arqueológico. ${ }^{43}$

O maior debate, no entanto, se dá em torno da própria noção de invasão. Walter Goffart procurou caracterizar o processo de instalação de populações bárbaras como uma "acomodação". Quando grupos não-romanos adentraram o Império, na segunda metade do século IV, logo foram cooptados como elementos da política imperial, causando um impacto mínimo nas regiões onde se instalaram. Honório, por exemplo, estaria mais preocupado com usurpações do que com invasores, e usou os visigodos como forma de influir nos acontecimentos na Gália, na década após o saque de Roma. ${ }^{44}$ Guy Halsall, em diversas publicações, chamou a atenção para o fato de que as zo-

\footnotetext{
${ }^{41}$ GEARY, Patrick. Barbarians and ethnicity. In: BOWERSOCK, Glen; BROWN, Peter; GRABAR, André (org.). Late Antiquity. A guide to the postclassical world. Cambridge, MA: Harvard University Press, 1999, p. 114-115 e 119-120 (para godos e visigodos).

${ }^{42}$ VON RUMMEL, Philipp. The archaeology of 5th century Barbarians in north Africa. In: DELOGU, Paolo \& GASPARRI, Stefano (org.). Le trasformazioni del V secolo. L'Italia, i barbari e l'Occidente romano. Turnhout: Brepols, 2010, p. 159.

${ }^{43}$ VAN OSSEL, Paul. Rural impoverishment in northern Gaul at the end of Antiquity: the contribution of archaeology. In BOWDEN, Will; GUTTERIDGE, Adam; MACHADO, Carlos (org.). Social and political life in late Antiquity (Late antique archaeology 3.1). Leiden: Brill, 2006, p. 533-565. Von Rummel também observou a dificuldade de identificar assentamentos de vândalos no norte da África: VON RUMMEL, Philipp. The archaeology of 5th century Barbarians in north Africa. In DELOGU, Paolo \& GASPARRI, Stefano (org.). Le trasformazioni del V secolo. L'Italia, i barbari e l'Occidente romano. Turnhout: Brepols, 2010, p. 159-160.

${ }^{44}$ GOFFART, Walter. Barbarians and Romans A. D. 418-584: The techniques of accommodation. Princeton: Princeton University Press, 1980.
} 
nas onde os povos bárbaros se instalaram eram áreas onde o poder imperial havia colapsado e que isso era uma forma de manter a ordem. ${ }^{45}$

Halsall está coberto de razão quando afirma que muitas das lideranças germânicas eram bastante integradas a corte e sociedade romanas. Mais ainda quando recusa a ideia de que os grupos que conhecemos através das fontes escritas, como os visigodos de Alarico, possam ser identificados como grupos étnicos ou mesmo tribos: eram grupos de guerreiros não-romanos, cuja identidade estava em constante reconstrução. ${ }^{46}$ As diferenças entre Alarico (o saqueador de Roma) e Estilicão (general que por duas décadas governara o Ocidente), e entre os bárbaros que os seguiam, eram mais de grau do que de natureza, e a campanha de difamação movida contra Estilicão após sua queda em 408 mostra isso; o fato de que seus soldados passaram para o lado de Alarico em seguida o confirma. ${ }^{47}$

Mesmo nossas fontes literárias mais ricas para os eventos de 406 na Gália, os comentários e cartas de Jerônimo mencionados acima, colocam problemas de interpretação. Stefan Rebenich observou que, ao tratar desses eventos dos quais ouviu falar durante sua estada na Palestina, Jerônimo procurou apresentá-los como parte de uma reflexão histórica e teológica mais ampla, e não simplesmente em descrevê-los. Além de seus relatos serem confusos, misturando povos, personagens e datas, seus modelos literários são Tito Lívio e o saque gaulês de Roma, Virgílio e o Antigo Testamento. ${ }^{48} \mathrm{Ou}$ seja, não é mais possível ler nossas fontes de maneira ingênua, sem prestar atenção não só às suas inconsistências internas e às intenções de seus autores, mas também aos seus modelos literários.

Isso não quer dizer que devamos abandonar a ideia de que as invasões aconteceram e que tiveram consequências, por vezes dramáticas. Contra os argumentos de Halsall, Peter Heather observou que, em 408, Radagaiso invadiu a Itália em um momento em que a corte não estava distraída por Alarico ou pelo Oriente (ao contrário de 406), e o bárbaro que tanto aterrorizara

\footnotetext{
${ }^{45}$ HALSALL, Guy. The Barbarian invasions. In: FOURACRE, Paul (org.). The new Cambridge medieval history, vol. 1, c. 500-c. 700. Cambridge: Cambridge University Press, 2005, p. 49.

46 Suas ideias são apresentadas de maneira mais extensa em HALSALL, Guy. Barbarian migrations and the Roman West, 376-568. Cambridge: Cambridge University Press, 2007.

${ }^{47}$ Ver a narrativa de Zósimo, 5.35.1-6.

${ }^{48}$ REBENICH, Stephen. Christian asceticism and Barbarian incursion: The making of a Christian catastrophe. Journal of Late Antiquity. Baltimore, n. 2, 2009, p. 49-59.
} 
Orósio foi devidamente derrotado. ${ }^{49}$ Ou seja, quando o Império se encontrava em condições de se defender, ele o fazia. A perda de territórios teve um impacto poderoso na base fiscal do Império, como observou Chris Wickham em $1984 .^{50}$ A retirada das tropas e a retração do governo imperial também tiveram um impacto significativo para as populações do Império na parte ocidental. Como observou Ward-Perkins, no final do século V, a cultura material das ilhas britânicas havia involuído para níveis de complexidade e sofisticação inferiores aos dos séculos anteriores à conquista romana, abandonando o uso de moedas, do torno mecânico para a produção de cerâmica e das cidades como forma de assentamento. ${ }^{51}$ Se, por um lado, não havia uma oposição clara e rigidamente definida entre romanos e bárbaros (mesmo a ideologia era flexível), por outro lado, as invasões tiveram um efeito real na estrutura social e política da época. Pode-se argumentar que, segundo a perspectiva geográfica mais ampla advogada por Brown e seus seguidores, a história do Império precisa ser reavaliada em conjunto com a história dos povos vizinhos que também fizeram parte da Antiguidade tardia. Por outro lado, essa nova história, mais ampla, ainda precisa lidar com a ideia de que o Império caiu, ao menos no Ocidente, e que as "invasões bárbaras" exerceram um papel importante nesse processo.

\section{Entre rupturas e continuidades: a cidade na Antiguidade tardia}

O problema, assim, não é decidir se estamos lidando com um período de rupturas ou continuidades: todos os períodos históricos são marcados por rupturas $e$ por continuidades. O problema reside em entender como é que estes elementos foram combinados, levando em conta o fato de que esta combinação variou de acordo com a região que estudamos e com o passar do tempo. Isso pode ser melhor considerado quando pensamos no caso da evolução das cidades - entendidas como forma de organização social e política

\footnotetext{
${ }^{49}$ HEATHER, Peter. Why did the Barbarians cross the Rhine?. Journal of Late Antiquity. Baltimore, n. 2, 2009, p. 20.

${ }^{50}$ WICKHAM, Chris. The other transition: From the ancient world to feudalism. Past and Present. Londres, n. 103, 1984, p. 16. Wickham retoma esta mesma ideia em The inheritance of Rome. $A$ history of Europe from 400 to 1000. Londres: Penguin, 2010, p. 83.

${ }^{51}$ WARD-PERKINS, Bryan. Specialized production and exchange. In: CAMERON, Averil; WARD-PERKINS, Bryan; WHITBY, Michael (org.). The Cambridge ancient history, v. 14: Late Antiquity and its successors, A. D. 420-600. Cambridge: Cambridge University Press, 2000, p. 350-352.
} 
rev. hist. (São Paulo), n. 173, p. 81-114, jul.-dez., 2015 http://dx.doi.org/10.11606/issn.2316-9141.rh.2015.105844
Carlos Augusto Ribeiro Machado

A Antiguidade tardia, a queda do Império romano e o debate sobre o "fim do mundo antigo"

no espaço - durante a Antiguidade tardia. Seria impossível discutir esse tema de forma extensa e detalhada aqui, mas podemos ao menos observar o modo como o problema é colocado por diversos estudiosos, e procurar apreender as linhas de força mais gerais que caracterizam esta discussão.

Durante toda a Antiguidade, as cidades permaneceram sendo a forma mais característica - pode-se dizer definidora - de assentamento, de ocupação do espaço e de organização social. Este aspecto se torna ainda mais relevante quando se considera que, nos séculos seguintes, cidades continuaram a ser importantes, mas em uma escala diversa e exercendo funções diferentes. ${ }^{52} \mathrm{O}$ "fim da cidade antiga", ou seja, o declínio de um tipo de organização baseado na relativa autonomia política e financeira, governada por assembleias populares e conselhos formados por membros da elite, e que se materializava fisicamente em espaços públicos financiados ao menos em parte pelas elites locais, é um tema que atraiu enorme atenção nos últimos anos. ${ }^{53}$ Jones, no Later Roman Empire, utilizou-se de textos legislativos e inscrições para argumentar que esse declínio foi causado pelo crescimento do peso administrativo e fiscal do Estado imperial sobre as cidades, ocasionando o que a historiografia costumava chamar de "fuga dos decuriões" ${ }^{54}$ Grosso modo, as elites tradicionais que haviam financiado e liderado a vida cívica antiga se recusaram cada vez mais a assumir o peso da administração e governo citadinos, levando ao declínio das instituições políticas e de formas de relação social que eram fundamentais para o funcionamento da "cidade antiga".

O processo não foi assim tão simples e Jones estava ciente disso. Seu aluno J. H. W. G. Liebeschuetz (que preparou o index analítico do LRE) publicou em 1972 sua tese sobre Antioquia no século IV, mostrando que, ao

\footnotetext{
${ }^{52}$ Um bom ponto de partida para o lugar das cidades no alto Medievo é WICKHAM, Chris. Framing the early Middle Ages. Europe and the Mediterranean, 400-800. Oxford: Oxford University Press, 2005, p. 591-692. As discussões recentes sobre o lugar das cidades na sociedade e especialmente economia do alto Medieval, muito influenciadas pela arqueologia, se concentram no seu papel comercial: ver os artigos reunidos em GELICHI, Sauro \& HODGES, Richard (org.). From one sea to another: Trading places in the European and Mediterranean early Middle Ages. Turnhout: Brepols, 2012.

53 Para uma excelente discussão do papel das cidades no Império, ver CRACCO RUGGINI, Lellia La città imperiale. In: Storia di Roma, v. 4: Caratteri e morfologie. Turim: Einaudi, 1989, p. 201-266.

${ }^{54}$ JONES, A. H. M. The later Roman Empire 284-602. A social, economic, and administrative survey, 3 vol. Oxford: Basil Blackwell, 1964, p. 712-766. Para uma avaliação crítica (especialmente do ponto de vista da arqueologia) do que Jones escreveu, ver LAVAN, Luke A. H. M. Jones and "The cities", 1964-2004. In: GWYNN, David (org.). A. H. M. Jones and the later Roman Empire. Leiden: Brill, 2008, p. 167-192.
} 
menos no Oriente, cidades floresceram durante este período. ${ }^{55}$ Isso foi confirmado pelos trabalhos de Clive Foss sobre Sardis e Éfeso. ${ }^{56}$ Para o Ocidente, Ward-Perkins estudou o processo de mudança urbana na Itália central e setentrional entre 300 e 800, mostrando a presença de duas dinâmicas: por um lado, as elites locais e imperiais deixaram progressivamente de investir em estruturas clássicas, como termas e basílicas. Por outro lado, investiram cada vez mais nos espaços públicos que ainda eram significativos, especialmente igrejas. ${ }^{57} \mathrm{O}$ estudo fundamental (porque mais abrangente) para o Ocidente, no entanto, foi o de Claude Lepelley, sobre as cidades da África romana. ${ }^{58}$ Partindo de um vasto corpus epigráfico e literário, Lepelley mostrou uma impressionante continuidade das instituições cívicas e - igualmente importante - do orgulho citadino.

O progresso das técnicas arqueológicas e, especialmente, um interesse maior pela estratigrafia de fases mais recentes mostram que, em diversas áreas do Império, cidades continuaram a ser embelezadas e seus centros cívicos continuaram a ser restaurados. ${ }^{59}$ Uma maior atenção à epigrafia tardo-antiga também representou um progresso importante. A publicação de Aphrodisias in late Antiquity, por Charlotte Roueché (agora online), contribuiu para confirmar a continuidade de instituições e práticas cívicas clássicas em uma importante cidade da Cária na Turquia. ${ }^{60} \mathrm{O}$ caso de Aphrodisias é paradigmático: um sítio bem preservado e cuidadosamente escavado, no qual diversas fases da história da cidade, desde o final do período republicano, vêm sendo cuidado-

\footnotetext{
${ }^{55}$ LIEBESCHUETZ, Johann. H. W. G. Antioch: City and imperial administration in the later Roman Empire. Oxford: Oxford University Press, 1972. Ele foi precedido por PETIT, Paul. Libanius et la vie municipale à Antioche au IVe siècle aprés J.-C., Paris: Presses Universitaires de France, 1955. Note-se que a importância de Antioquia neste debate vem do fato de que boa parte dos escritos de Libânio, um membro da elite local, sobreviveram.

${ }^{56}$ FOSS, Clive. Byzantine and Turkish Sardis. Cambridge, MA: Harvard University Press, 1976; e Ephesus after Antiquity. Cambridge: Cambridge University Press, 1979.

57 WARD-PERKINS, Bryan. From classical Antiquity to the early Middle Ages. Urban public building in norther and central Italy, A. D. 300-800, Oxford: Oxford University Press, 1984.

${ }^{58}$ LEPELLEY, Claude. Les cités de l'Afrique romaine, vol. 1: La permanence d'une civilisation municipale. Paris: Études Augustiniennes, 1979. Um segundo volume, reunindo as fontes, foi publicado em 1981.

${ }^{59}$ A melhor e mais completa discussão permanece sendo a de LAVAN, Luke. Fora and agorai in Mediterranean cities during the 4th and 5th c. A. D. In: BOWDEN, Will; GUTTERIDGE, Adam; MACHADO, Carlos (org.). Social and political life in late Antiquity (Late antique archaeology 3.1). Leiden: Brill, 2006, p. 195-249.

${ }^{60}$ Disponível em: http://insaph.kcl.ac.uk/ala2004/. Acesso em: 18/07/2013.
} 
rev. hist. (São Paulo), n. 173, p. 81-114, jul.-dez., 2015 http://dx.doi.org/10.11606/issn.2316-9141.rh.2015.105844
Carlos Augusto Ribeiro Machado

A Antiguidade tardia, a queda do Império romano e o debate sobre o "fim do mundo antigo"

sa e sistematicamente publicadas. ${ }^{61}$ Além de bem preservadas, as estruturas publicas da cidade revelaram-se ricas em inscrições e decoração escultórea, o que permitiu a R. R. R. Smith reconstruir diversos conjuntos estatuários com suas bases inscritas. ${ }^{62}$ Isso não significa que não tenham ocorrido mudanças importantes: o estádio, apesar de bem preservado e provavelmente ainda em uso, fora incorporado à muralha da cidade, construída no século IV, e o famoso templo de Afrodite, que dera o nome à cidade, foi convertido em uma igreja dedicada à Virgem Maria. ${ }^{63}$ Enquanto em 1967 Dietrich Claude publicou seu monumental Die Byzantinische Stadt im 6. Jahrhundert, descrevendo as decadentes instituições cívicas da cidade clássica, 30 anos mais tarde, Franz Alto Bauer dedicou seu Stadt, Platz und Denkmal in der Spätantike à análise das obras públicas realizadas em Roma, Constantinopla e Éfeso, argumentando que o restauro de estruturas públicas podia ser lido como sinal de orgulho cívico e autopromoção de imperadores e membros das elites locais. ${ }^{64}$ No caso das cidades, como em outros campos da Antiguidade tardia, a ênfase na continuidade e a adoção de uma perspectiva mais otimista se tornaram a tônica. A "queda do Império romano" tornou-se, assim, um elemento desnecessário, e a interpretação de Jones sobre a fuga dos decuriões, obsoleta.

Esse quadro começou a ser revisto a partir de finais dos anos 1990. Ward-Perkins chamou a atenção para o fato de que - apesar de toda a evidência para a manutenção e restauro que vinha sendo publicada por arqueólogos e epigrafistas - diversas cidades do Ocidente apresentam indícios de

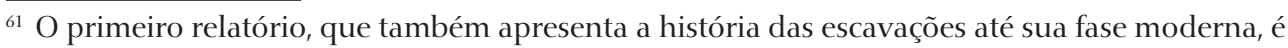
ERIM, Kenan. De Aphrodisiade. American Journal of Archaeology. Boston, n. 71, 1967, p. 233-243. Erim publicou uma síntese antes de falecer prematuramente: ERIM, Kenan. Aphrodisias, city of Venus Aphrodite. Londres: Muller, Blond and White, 1986. Relatórios periódicos são publicados pelos atuais diretores das escavações, R. R. R. Smith e C. Ratté, no American Journal of Archaeology; e o Journal of Roman Archaeology publicou uma série de volumes suplementares com o título Aphrodisias papers.

${ }^{62}$ SMITH, Roland. R. R. Late Antique portraits in a public context: Honorific statuary at Aphrodisias in Caria, A. D. 300-600. Journal of Roman Studies. Londres, n. 89, 1999, p. 155-189. Mais recentemente: Idem. Statue life in the Hadrianic baths at Aphrodisias, A. D. 100-600: Local context and historical meaning. In: BAUER, Franz Alto \& WITSCHEL, Christian (orgs.). Statuen in der Spätantike. Wiesbaden: Reichert Verlag, 2007, p. 203-235.

${ }^{63}$ Ver SMITH, Roland. R. R. \& RATTÉ, Christopher. Archaeological research at Aphrodisias in Caria, 1994. American Journal of Archaeology. Boston, n. 100, 1996, p. 20-21. Para o templo de Afrodite, ver CORMACK, Robin. Byzantine Aphrodisias: changing the symbolic map of a city. Proceedings of the Cambridge Philological Society. Cambridge, n. 216, 1990, p. 26-41.

${ }^{64}$ CLAUDE, Dietrich. Die Byzantinische Stadt im 6. Jahrhundert. Munique: Beck, 1967. BAUER, Franz Alto. Stadt, Platz und Denkmal in der Spätantike: Untersuchungen zur Ausstatung des öffentlichen Raums in den spätantiken Städten Rom, Konstantinopel und Ephesos. Mainz: von Zabern, 1996.
} 
rev. hist. (São Paulo), n. 173, p. 81-114, jul.-dez., 2015 http://dx.doi.org/10.11606/issn.2316-9141.rh.2015.105844
Carlos Augusto Ribeiro Machado

A Antiguidade tardia, a queda do Império romano e o debate sobre o "fim do mundo antigo"

abandono de áreas públicas e de estruturas públicas e conversão de estruturas cívicas para novos usos. ${ }^{65}$ Nem mesmo Roma, a antiga capital imperial e ainda maior cidade do Mediterrâneo, escapou dessa evolução: partes da cidade foram abandonadas ou perderam sua função monumental (como é o caso da Crypta Balbi, por exemplo), enquanto alguns poucos centros permaneceram foco de investimento por parte das autoridades, como o Fórum romano. ${ }^{66}$ Esse processo já era visto no caso das cidades ocidentais no século IV, e se intensificou no século V. No caso do Oriente, ele se torna mais visível nos séculos VI e VII. ${ }^{67}$ Esse processo de "valorização seletiva" (e, em um segundo momento, de "declínio controlado") é de suma importância para que possamos compreender a evolução das cidades durante esse período. Autores que tomam indícios de restaurações como sinal de continuidade correm o risco de ignorar o quadro mais geral de mutações importantes.

Em seu famoso (e já citado) artigo de 1993, Carandini observou (ou relembrou) que continuidade de sítio não implica necessariamente em continuidade social: uma sociedade pode mudar, mesmo habitando as mesmas estruturas. ${ }^{68}$ Essa é a mesma perspectiva de Liebeschuetz em seu Decline and fall of the Roman city (uma clara alusão à obra de Gibbon) de 2001. ${ }^{69}$ Como Ward-Perkins, Liebeschuetz argumenta que os restauros seletivos e as novas construções, especialmente igrejas, estão ligados ao desenvolvimento de uma nova sociedade, na qual a comunidade cívica clássica deu lugar à comunidade cristã. As cidades se transformavam fisicamente, ao mesmo tempo em que as sociedades que nelas viviam também se transformavam.

\footnotetext{
65 O problema foi identificado em WARD-PERKINS, Bryan. Continuists, catastrophists, and the towns of post-Roman northern Italy. Papers of the British School at Rome. Londres, n. 65, 1997, p. 157-176; foi retomado em WARD-PERKINS, Bryan. The cities. In: GARNSEY, Peter \& CAMERON, Averil (org.). The Cambridge ancient history, vol. XIII: The late Empire, A. D. 337-425. Cambridge: Cambridge University Press, 1998, p. 382.

${ }^{66}$ Para a refuncionalização e abandono progressivo da Crypta Balbi, ver MANACORDA, Daniele. Crypta Balbi. Archeologia e storia di un paesaggio urbano. Milão: Electa, 2001, p. 44-45. Para o Forum romano, ver MACHADO, Carlos. Building the past: Monuments and memory in the Forum Romanum. In: BOWDEN, Will; GUTTERIDGE, Adam; MACHADO, Carlos (org.). Social and political life in late Antiquity (Late antique archaeology 3.1). Leiden: Brill, 2006, p. 157-192.

${ }^{67}$ Como observa LIEBESCHUETZ, Johann. H. W. G. The decline and fall of the Roman city. Oxford: Oxford University Press, 2001, p. 43, para a Anatólia.

${ }^{68}$ CARANDINI, Andrea. L'ultima civiltà sepolta o del massimo oggetto desueto, secondo un archeologo. In: CARANDINI, Andrea; CRACCO RUGGINI, Lellia; GIARDINA, Andrea (org.). Storia di Roma, vol. 3: L'età tardoantica, tomo 2: I luoghi e le culture. Turim: Einaudi, 1993, p. 15.

${ }^{69}$ LIEBESCHUETZ, Johann.H.W.G. The declineandfall of theRomancity.Oxford:OxfordUniversity Press, 2001.
} 
Este processo também foi discutido por Peter Brown que analisou a substituição das elites tradicionais pelas lideranças cristãs. ${ }^{70}$ No entanto, ao invés de enfatizar a "fuga dos decuriões", como Jones, ou o "declínio da cidade romana", como Liebeschuetz, Brown enfatiza a continuidade, argumentando que as novas elites eclesiásticas comungaram dos mesmos ideais e formação cultural das elites seculares do século IV (em grande medida já cristianizadas, ao menos no Oriente) - a paideia, um conjunto de valores transmitidos através da educação formal, no qual a retórica e os ideais culturais clássicos exerciam um papel central. ${ }^{71}$

O problema com a perspectiva de Brown é que ela enfatiza uma (efetiva) continuidade das formas culturais em detrimento de uma imensa transformação social. Os trabalhos de Liebeschuetz e Avshalom Laniado mostraram que o governo das cidades não passou imediatamente para os bispos, mas, sim, para os principales, uma elite extremamente rica com contatos na corte imperial e cuja posição política e econômica prescindia das tradicionais estruturas cívicas - os maiores beneficiários das consequências das políticas econômicas de Constantino, discutidas acima. ${ }^{72}$ Recentemente, Luke Lavan criticou essa perspectiva, observando que só é possível descrever estes processos como "declínio" se tomarmos como ponto de partida uma concepção liberal do que seria a cidade-antiga "clássica", baseada em instituições políticas de tipo deliberativo e na participação política. ${ }^{73}$ Essa é uma crítica importante, da qual devemos estar conscientes, mas que não resolve o problema central para nossa discussão: uma sociedade governada por uns poucos potentes, em colaboração com as autoridades eclesiásticas, mesmo que educados segundo os preceitos da paideia clássica, é uma sociedade muito diferente de outra na qual setores mais amplos da sociedade (ainda que não todos) têm acesso às instituições de governo e à administração local.

Governo com participação popular, mesmo que limitada, não implica necessariamente em uma sociedade mais justa do que uma governada por

\footnotetext{
${ }^{70}$ Em BROWN, Peter. Power and persuasion in late Antiquity. Madison: University of Wisconsin Press, 1992.

${ }^{71}$ Para a importância da paideia como um elemento unificador das elites, ver CARVALHO, Margarida de. Paideia e retórica no século IV d. C.: A construção da imagem do imperador Juliano segundo Gregório Nazianzeno. São Paulo: Annablume, 2010, p. 25-26.

${ }^{72}$ LIEBESCHUETZ, Johann. H. W. G. The decline and fall of the Roman city. Oxford: Oxford University Press, 2001, p. 110-120. LANIADO, Avshalon. Recherches sur les notables municipaux dans l'empire protobyzantin. Paris: Centre d'Histoire et Civilisation de Byzance, 2002.

${ }^{73}$ LAVAN, Luke. Christianity, the city and the end of Antiquity. Journal of Roman Archaeology. Portsmouth, n. 16, 2003, p. 709.
} 
"notáveis". Essa é uma discussão mais ideológica do que propriamente histórica, e a discussão está mal colocada nestes termos. O que nos interessa aqui é discutir o modo como iremos caracterizar as sociedades tardo-antigas. A relação entre continuidade e declínio foi retomada por Lepelley recentemente, com relação às cidades da África. ${ }^{74}$ Segundo este autor, as fortes continuidades observáveis entre os séculos II e IV sugerem que devemos reconsiderar a ideia de que a Antiguidade tardia seja um período autônomo. Para ele, a região já passava por um período de decadência econômica no início do século $V$, e a invasão vândala não chegou a representar uma ruptura. Esta só é observável após a reconquista bizantina, quando sinais de abandono e espoliação de cidades ficam mais claros (basta pensarmos no Fórum de Dougga, por exemplo). Mesmo assim, esse foi um período de intensa monumentalização cristã, o que indicaria uma relativa continuidade, em meio a importantes mudanças.

Lepelley cita uma inscrição, datável de 540-543, recordando a construção de uma fortaleza bizantina na Tunísia central, que é de especial interesse para nós:

Essa obra e estas fortificações são devidas à afortunada autoridade imperial, e às ordens do magnânimo Salomão, que o tribuno Nonnus, que realizou estes trabalhos, obedeceu. Cidade, regozije por ter este senhor pio e veja de quantos males foste subtraída e com quantos ornamentos foste embelezada. Enfim livre do medo dos Mouros, reencontras a capacidade de organizar o censo, um estatuto, os cidadãos, o direito, as construções públicas e os fasti; e a esposa do rei lhe concedeu seu nome, a mão de Justiniano tendo colocado o povo dos Mouros em fuga. ${ }^{75}$ Tudo tem seu tempo: e os povos (bárbaros) lamentavam suas circunstâncias. ${ }^{76}$

\footnotetext{
${ }^{74}$ LEPELLEY, Claude. La cité africaine tardive, de l'apogée du IVe siècle à l'effondrement du VII siècle. In: KRAUSE, Jens-Uwe \& WITSCHEL, Christian. (org.). Die Stadt in der Spätantike - Niedergang oder Wandel?. Stuttgart: Franz Steiner Verlag, 2006, p. 13-31.

${ }^{75}$ A cidade, identificada como Cululis, recebeu o nome de Teodoriana, da esposa de Justiniano.

${ }^{76}$ L'Année Épigraphique 2002, 1666=1996, 1704: "Hoc opus imperium felix has prestitit arces, / Magnanimique etiam Solomonis iussa dedere, / Cui paruit Nonnus, qui condidit ista tribunus. / Urbs domino laetare pio, iamque aspice quantis / Es subducta malis, quantoque or[n]ata decore. / Maurorum tandem recipis subducta timore / Censuram, statum, cives, ius, moenia, fastus; / Atque suum nomen posuit $\langle\nabla>i b i$ regia coniunx, / Iu(s)tiniani manu Maurorum gente fugata. / Omnia tempus (h)abent: flebant et (t)em[por]a gentes." Para a edição mais recente, adotada aqui, ver PRINGLE, Denys. Two fortified sites in Byzantine Africa: Aïn Djelloula and Henchir Sguidan. Antiquité Tardive. Turnhout, n. 10, 2002, p. 274. LEPELLEY, Claude. La cité africaine tardive, de l'apogée du IVe siècle à l'effondrement du VII siècle. In:
} 
rev. hist. (São Paulo), n. 173, p. 81-114, jul.-dez., 2015 http://dx.doi.org/10.11606/issn.2316-9141.rh.2015.105844
Carlos Augusto Ribeiro Machado

A Antiguidade tardia, a queda do Império romano e o debate sobre o "fim do mundo antigo"

Yves Modéran publicou um importante estudo dessa inscrição, no qual argumentou que as referências ao censo, estatuto, cidadãos, construções públicas (moenia) e aos fasti, as tradicionais listas de oficiais encarregados do governo da cidade, são prova da continuidade da cidade antiga em pleno século VI.77 O problema é que, apesar de afirmar exatamente isso textualmente, a inscrição precisa ser tomada em seu contexto: uma inscrição métrica (em verso), celebrando a piedade, a vitória e a generosidade do imperador e de seus oficiais após a conquista sobre os vândalos e em um momento de conflito contra os mouros, certamente é um texto com altíssima carga ideológica. Mais importante ainda é o contexto de descoberta deste texto, não em uma das tradicionais áreas públicas de uma cidade, mas entre as ruínas do portão de entrada de uma fortificação próxima à antiga cidade de Cululis. ${ }^{78}$ Apesar de toda a referência ao esplendor da vida cívica, o contexto de exposição da inscrição (assim como a referência à fortaleza, no texto) sugere uma situação muito diferente daquela do século IV. Trata-se, de fato, do único texto de que dispomos que faz referência às instituições e práticas que marcaram a vida cívica clássica, e somos obrigados a nos perguntar se isso não se trataria, na verdade, de uma "veleidade manifestando nostalgia", como bem observou Lepelley. ${ }^{79}$

Uma maneira de se lidar com a questão de como rupturas e continuidades foram combinadas é considerar uma prática específica, intimamente ligada aos ritmos e à cultura cívica da época clássica, o assim chamado "hábito estatuário". Durante todo o período imperial romano, em quase todo o Império (mas especialmente na Itália, África, Grécia e Ásia Menor), comunidades e grupos citadinos votaram estátuas honoríficas para imperadores, governadores, membros da elite local, atletas, poetas e divindades. Estátuas eram colocadas em espaços públicos como uma forma de expressar a gratidão da comunidade por algum benefício ou como demonstração de lealdade política a imperadores e oficiais imperiais. A prática servia, assim, como uma

KRAUSE, Jens-Uwe $\mathcal{E}$ WITSCHEL, Christian (org.). Die Stadt in der Spätantike - Niedergang oder Wandel?. Stuttgart: Franz Steiner Verlag, 2006, p. 20.

${ }^{77}$ MODÉRAN, Yves. La renaissance des cités dans l'Afrique du VIe siècle d'après une inscription récemment publiée. In: LEPELLEY, Claude (org.). La fin de la cité antique et le début de la cité médiévale. Bari: Edipuglia, 1996, p. 85-114.

${ }^{78}$ PRINGLE, Denys. Two fortified sites in Byzantine Africa: Aïn Djelloula and Henchir Sguidan. Antiquité Tardive. Turnhout, n. 10, 2002, p. 274.

${ }^{79}$ LEPELLEY, Claude. La cité africaine tardive, de l'apogée du IVe siècle à l'effondrement du VII siècle. In: KRAUSE, Jens-Uwe E W WITSCHEL, Christian. (org.). Die Stadt in der Spätantike - Niedergang oder Wandel?. Stuttgart: Franz Steiner Verlag, 2006, p. 21. 
forma de "azeitar" as engrenagens do governo imperial e local, e o fato de requerer ou uma decisão da autoridade competente ou uma votação por parte de uma das assembleias citadinas faz com que essa seja uma forma muito rica de se analisar a evolução da vida cívica durante a Antiguidade tardia. Esta prática foi objeto de estudo do projeto "The last statues of Antiquity", dirigido por Bryan Ward-Perkins e R. R. R. Smith, de Oxford, que produziu um banco de dados online coletando todas as evidências escultórea, epigráfica e literária relativas à produção e dedicação de estátuas de todo o Império entre o final do século III e o início do século VII. ${ }^{80}$

O que o projeto demonstrou foi que a prática de dedicar estátuas continuou importante no século IV, especialmente em Grécia, Ásia Menor, Itália e África. ${ }^{81}$ De fato, mesmo estátuas de imperadores cristãos tinham um estatuto sagrado e ataques a estas imagens eram passíveis de punições duras, como o povo de Antioquia aprendeu em 387. ${ }^{82}$ Estátuas continuavam a ser dedicadas pelos mesmos motivos que nos séculos anteriores, apesar de diferentes regiões seguirem padrões diversos. O número de estátuas dedicadas a membros das elites locais caiu em todo o Império, quando comparado aos séculos anteriores. Ao mesmo tempo, estátuas de imperadores e altos funcionários (estas, porém, em número muito menor) passaram a dominar a paisagem urbana de um modo ainda mais enfático do que no alto Império. $\mathrm{O}$ hábito estatuário ficou, de modo mais evidente do que nunca, associado ao poder imperial e a seus oficiais, em detrimento das antigas magistraturas e lideranças citadinas. As únicas exceções a este padrão imperial são encontradas no sul da Itália e em Roma, onde se percebe uma forte predominância de estátuas de governadores de províncias, normalmente senadores romanos que possuíam terras e vínculos de patronagem com as comunidades locais. Não é coincidência que estas sejam as regiões mais ricas em termos de material disponível, o que sugere que, apesar de a prática ter continuado, havia um grau de coerção muito maior sobre as comunidades por parte de seus patronos poderosos. O número de estátuas dedicadas declinou em todo o Império, tendo desaparecido em quase todas as províncias após a metade do

\footnotetext{
${ }^{80} \mathrm{O}$ banco de dados pode ser pesquisado em: http://laststatues.classics.ox.ac.uk/. Acesso em: 19/07/2013.

${ }^{81}$ Sintetizo, aqui, os resultados do projeto, que aparecerão em SMITH, Roland. R. R. \& WARD-PERKINS, Bryan (org.). The last statues of Antiquity. Oxford: Oxford University Press (no prelo).

${ }^{82}$ Como discute SILVA, Erica. Conflito politico-cultural na Antiguidade tardia: $O$ "levante das estátuas" em Antioquia de Orontes (387 d. C.). Tese de doutoramento, Unesp, Franca, 2012.
} 
século IV, no sul da Itália por volta de 400, e em Roma, continuando muito pequeno até o final do século $\mathrm{V}$.

As fontes epigráficas revelam que, ao mesmo tempo em que o número de estátuas declinava, as estátuas ainda dedicadas o eram por um grupo cada vez mais restrito de agentes. Enquanto, no início do século IV, pequenos e altos funcionários imperiais, senadores, corporações, cidades, províncias e pessoas poderosas participavam desse hábito, por volta de 400, apenas altos funcionários o faziam. ${ }^{83}$ Isso pode ser explicado ao menos de duas maneiras: a) as instituições e formas clássicas de vida cívica e a política participativa que haviam animado o hábito estatuário dos séculos anteriores perderam importância na vida urbana; b) novas formas de celebração da comunidade, de seus valores e de seus líderes, como mosaicos em igrejas e aclamações no circo, ganharam importância. Isso não quer dizer que o povo não encontrasse formas de participação política, formais ou informais. ${ }^{84}$ Estas, no entanto, independiam das - e em em larga medida sobreviveram às - formas e instituições que haviam caracterizado a cidade clássica.

Estátuas continuaram sendo dedicadas como, por exemplo, o grupo de monumentos comemorando Porfírio, o corredor do circo, em Constantinopla do início do século VI; ${ }^{85}$ ou a estátua colocada pelo exarca bizantino Smaragdo, honrando o imperador Focas, no Fórum romano. ${ }^{86}$ Estas foram iniciativas isoladas, no entanto, e, mais do que continuidade, parecem indicar um interesse renovado pelo passado e suas práticas, buscando uma forma de legitimação fundamentada no tradicionalismo. Uma mesma atitude que encontramos nas Variae de Cassiodoro, assim como nas Parastaseis syntomoi chronikai e Patria, de Constantinopla. ${ }^{87}$ Quando Zacarias de Mitilene, no século VI, elencou as

\footnotetext{
${ }^{85}$ Para uma análise detalhada do caso italiano, para o qual dispomos de melhor documentação, ver MACHADO, Carlos. Public monuments and civic life: The end of the statue habit in Italy. In: DELOGU, Paolo \& GASPARRI, Stefano (org.). Le trasformazioni del $V$ secolo. L'Italia, i barbari e l'Occidente romano. Turnhout: Brepols, 2010, p. 237-257.

${ }^{84}$ Como bem demonstrado por OLIVEIRA, Julio Cesar. Le "pouvoir du people": une émeute à Hippone au début du Ve. siècle connue par le sermon 302 de saint Augustin pour la fête de saint Laurent. Antiquité Tardive. Turnhout, n. 12, 2004, p. 309-324.

${ }^{85}$ Estudados por CAMERON, Alan. Porphyrius the Charioteer. Oxford: Oxford University Press, 1973.

${ }^{86}$ Corpus Inscriptionum Latinarum VI, 1200.

${ }^{87}$ Sobre Cassiodoro e suas atitudes perante o passado e seus monumentos, ver FAUVINET-RANSON, Violaine. Decor Civitatis, Decor Italiae. Monuments, travaux publics et spectacles au VIe siècle d'après les Variae de Cassiodore. Bari: Edipuglia, 2006. CAMERON, Averil \& HERRIN, Judith. Constantinople in the early eighth century: The Parastaseis Syntomoi Chronikai. Leiden: Brill, 1984. DAGRON, Gilbert. Constantinople imaginaire. Études sur le recueil des "Patria". Paris: Presses Universitaires de France, 1984.
} 
estátuas que existiam na cidade de Roma (uma passagem de pouca credibilidade factual, mas imensamente importante pelo que ela revela sobre sua cultura), ele mencionou milhares de monumentos, inclusive 25 estátuas de bronze da família de Abraão e da linha de Davi. ${ }^{88} \mathrm{O}$ hábito estatuário continuava presente como elemento físico na paisagem urbana, mas não era uma instituição organicamente integrada - à maneira clássica - à vida da cidade.

\section{Conclusão}

É impossível, nesse momento, oferecer uma explicação satisfatória para o declínio do hábito estatuário. ${ }^{89} \mathrm{O}$ que me parece claro, no entanto, é que este processo esteve ligado a pelo menos três desenvolvimentos que nos interessam diretamente e que envolveram o declínio da cidade antiga:

1) A maior presença e o maior peso da autoridade imperial e do aparato governamental, verificável a partir das reformas promovidas por Diocleciano e Constantino no final do século III e no início do século IV. Isso esteve diretamente ligado à crise dos conselhos citadinos (as curiae) e fica aparente no progressivo desaparecimento de estátuas de magistrados locais.

2) A consolidação de um abismo socioeconômico separando as camadas mais frágeis das mais poderosas da sociedade tardo-antiga, um abismo consolidado pela introdução do solidus ainda no início do século IV, que teve sua correspondência no declínio das formas clássicas de associação política - observável no desaparecimento de estátuas dedicadas pelas associações cívicas locais.

3) A incapacidade do aparato estatal de se financiar e garantir a defesa das áreas sob seu domínio, o que levou, em termos mais gerais, à perda de territórios, mas, em termos locais, ao desaparecimento de estruturas políticas e de governo imperiais. Como resultado, as autoridades eclesiásticas vieram a ocupar

\footnotetext{
${ }^{88}$ Publicado em VALENTINI, Roberto E ZUCCHETTI, Giuseppe (org.). Codice Topografico della Città di Roma, vol. 1. Roma: Tipografia del Senato, 1940, p. 332.

${ }^{89}$ LIVERANI, Paolo. The Sunset of 3D. In: KRISTENSEN, Troels \& STIRLING, Lea (org.). The afterlife of Roman sculpture: Late antique response and reception. Ann Arbor: The University of Michigan Press (no prelo), enfatiza a importância de se considerar também os desenvolvimentos artísticos e das formas de representação, especialmente a opção por formas de arte bidimensionais, em detrimento das tridimensionais.
} 
um papel de liderança cada vez mais marcado, desempenhando funções anteriormente associadas aos conselhos municipais e ao governo central.90

O Império romano nunca foi uma unidade social e cultural, e expressões como mundo antigo ou mundo romano, apesar de ainda úteis (e, por isso mesmo, repetidamente empregadas neste artigo), colocam-nos em risco de ignorar a enorme diversidade que caracterizava as sociedades conquistadas durante a expansão dos séculos precedentes. Estudiosos têm criticado de maneira cada vez mais vigorosa conceitos como romanização, ressaltando a vitalidade e especificidade da vida local e a diversidade de formas de integração dessas comunidades à ordem imperial. ${ }^{91}$ Por outro lado, é inegável que o Império teve um impacto real na vida dessas comunidades, agindo como uma estrutura política, administrativa e fiscal unificadora sobre um vasto território. Esse impacto só fez crescer durante o século IV, o que teve resultados importantíssimos para essas diversas comunidades. O desaparecimento dessa estrutura, inicialmente através da perda de territórios para grupos que optaram por se identificar explicitamente como não romanos, e em 476 (no Ocidente), através da remoção do último imperador legítimo e do envio das insignias imperiais para Constantinopla, pode, com certeza, ser identificado como uma dinâmica marcante na história deste período, mais do que um simples epifenômeno político.

Os estudiosos certamente ainda têm muito a discutir e a descobrir sobre o "mundo da Antiguidade tardia", seus limites cronológicos e geográficos, e como melhor caracterizá-lo. No entanto, é fundamental que continuemos a refletir e estudar também o velho tema de Montesquieu e Gibbon (e, a seu modo, Agostinho, séculos antes), a queda do Império. Ao mesmo tempo, como espero ter deixado claro, a história da Antiguidade tardia não se resume à "queda silenciosa" do Império romano (para usar a já citada expressão de Momigliano). Se há uma lição clara que pode ser depreendida dos trabalhos discutidos aqui é que a história das sociedades tardo-antigas não pode ser restrita, e nem confundida, com a história do Império romano - apesar de esta ainda merecer um destaque nesse processo. Ela é ao mesmo tempo muito mais ampla e mais específica do que isso. Ela requer novas aborda-

\footnotetext{
${ }^{90}$ Como bem observado, entre outros, pelo próprio BROWN, Peter. Poverty and leadership in the later Roman Empire. Hanover: Brandeis University Press, 2002.

${ }^{91}$ Para uma discussão desses problemas, ver WOOLF, Greg. Becoming Roman. The origins of provincial civilization in Gaul. Cambridge: Cambridge University Press, 1998.
} 
gens e novos horizontes teóricos, cronológicos e geográficos. Em suma, um novo modo de se pensar a história antiga.

\section{Referências bibliográficas}

BANAJI, Jairus. Agrarian change in late Antiquity. Oxford: Oxford University Press, 2001.

BAUER, Franz Alto. Stadt, Platz und Denkmal in der Spätantike: Untersuchungen zur Ausstatung des öffentlichen Raums in den spätantiken Städten Rom, Konstantinopel und Ephesos. Mainz: von Zabern, 1996.

BIANCHI BANDINELLI, R. Spaetantike. In: Enciclopedia dell'Arte Antica, vol. 7. Roma: Treccani, 1966, p. 426-427. Disponível em: http://www.treccani.it/enciclopedia/ spaetantike_(Enciclopedia-dell'-Arte-Antica)/. Acesso em: 15/07/2013.

BOWERSOCK, Glen; BROWN, Peter; GRABAR, André. Introduction. In: BOWERSOCK, Glen; BROWN, Peter; GRABAR, André (org.). Late Antiquity. A guide to the postclassical world. Cambridge, MA: Harvard University Press, 1999, p. vii-xiii.

BROWN, Peter. The world of late Antiquity: from Marcus Aurelius to Muhammad. Londres: Thames and Hudson, 1971.

. The later Roman Empire. In: Idem. Religion and society in the age of $\mathrm{Au}^{-}$ gustine of Hippo. Nova York: Harper $\mathcal{E}$ Row, 1972, p. 46-73.

Mohammed and Charlemagne by Henri Pirenne. In: Idem. Society and the holy in late Antiquity. Berkeley: University of California Press, 1982, p. 63-79. Press, 1992.

Power and persuasion in late Antiquity. Madison: University of Wisconsin

Poverty and leadership in the later Roman Empire. Hanover: Brandeis University Press, 2002.

Recovering submerged worlds. The New York Review of Books, 11 julho 2013. Disponível em: http://www.nybooks.com/articles/archives/2013/jul/11/ recovering-submerged-worlds/. Acesso em: 16/07/2013.

BROWN, P. et alii. The world of late Antiquity revisited. Symbolae Osloenses. Oslo, n. 72, 1997, p. 5-90.

CAMERON, Alan. Porphyrius the Charioteer. Oxford: Oxford University Press, 1973.

CAMERON, Averil. The Mediterranean world in late Antiquity. Londres: Routledge, 1995. Ideologies and agendas in late antique studies. In: LAVAN, Luke $\mathcal{E}$ BOWDEN, Will (org.). Theory and practice in late antique archaeology (Late antique archaeology 1). Leiden: Brill, 2003, p. 3-21.

CAMERON, Averil $\mathcal{E}$ HERRIN, Judith. Constantinople in the early eighth century: The Parastaseis Syntomoi Chronikai. Leiden: Brill, 1984.

CARANDINI, Andrea. L'ultima civiltà sepolta o del massimo oggetto desueto, secondo un archeologo. In: CARANDINI, Andrea; CRACCO RUGGINI, Lellia; GIARDINA, Andrea (org.). Storia di Roma, vol. 3: L'età tardoantica, tomo 2: I luoghi e le culture. Turim: Einaudi, 1993, p. 11-38. 
rev. hist. (São Paulo), n. 173, p. 81-114, jul.-dez., 2015 http://dx.doi.org/10.11606/issn.2316-9141.rh.2015.105844
Carlos Augusto Ribeiro Machado

A Antiguidade tardia, a queda do Império romano e o debate sobre o "fim do mundo antigo"

CARLÀ, Filippo. Il sistema monetario in età tardoantica: spunti per una revisione. Annali dell'Istituto Italiano di Numismatica. Roma, n. 53, 2007, p. 155-218.

CARRIÉ, Jean-Michel. Le "colonat" du bas-Empire: un mythe historiographique?, Opus. Roma, n. 1, 1982, p. 351-371.

CARRIÉ, Jean-Michel \& ROUSSELLE, Aline. L'Empire romain en mutation. Paris: Seuil, 1999.

CARVALHO, Margarida de. Paideia e retórica no século IV d. C.: A construção da imagem do imperador Juliano segundo Gregório Nazianzeno. São Paulo: Annablume, 2010.

CLAUDE, Dietrich. Die Byzantinische Stadt im 6. Jahrhundert. Munique: Beck, 1967.

CORMACK, Robin. Byzantine Aphrodisias: changing the symbolic map of a city. Proceedings of the Cambridge Philological Society. Cambridge, n. 216, 1990, p. 26-41.

COURCELLE, Pierre. Histoire littéraire des grandes invasions germaniques. Paris: Hachette, 1948.

CRACCO RUGGINI, Lellia. La città imperiale. In: Storia di Roma, v. 4: Caratteri e Morfologie. Turim: Einaudi, 1989, p. 201-266.

CURTA, Florin. Some remarks on ethnicity in medieval archaeology. Early Medieval Europe. Londres, n. 15, 2007, p. 160-161.

DAGRON, Gilbert. Constantinople imaginaire. Études sur le recueil des "Patria". Paris: Presses Universitaires de France, 1984.

ELSNER, J. The birth of late Antiquity: Riegl and Strzygowski in 1901. Art History. Londres, n. 25, 2002, p. 358-379.

ERIM, Kenan. De Aphrodisiade. American Journal of Archaeology. Boston, n. 71, 1967, p. 233-243.

Aphrodisias, city of Venus Aphrodite. Londres: Muller, Blond and White, 1986.

FAUVINET-RANSON, Violaine. Decor Civitatis, Decor Italiae. Monuments, travaux publics et spectacles au VIe siècle d'après les Variae de Cassiodore, Bari: Edipuglia, 2006.

FOSS, Clive. Byzantine and Turkish Sardis. Cambridge, MA: Harvard University Press, 1976. Ephesus after Antiquity. Cambridge: Cambridge University Press, 1979.

GASPARRI, Stefano $\mathcal{E}$ LA ROCCA, Cristina. Tempi barbarici. L'Europa occidentale tra Antichità e Medioevo (300-800). Roma: Carocci, 2012.

GEARY, Patrick. Barbarians and ethnicity. In: BOWERSOCK, Glen; BROWN, Peter; GRABAR, André (org.). Late Antiquity. A guide to the postclassical world. Cambridge, MA: Harvard University Press, 1999, p. 107-129.

GELICHI, Sauro \& HODGES, Richard (org.). From one sea to another: Trading places in the European and Mediterranean early Middle Ages. Turnhout: Brepols, 2012.

GIARDINA, Andrea. Esplosione di tardoantico. Studi Storici. Roma, n. 40, 1999, p. 157-180. Marxism and historiography: Perspectives on Roman history. In: WICKHAM, Chris (org.). Marxist history-writing for the twenty-first century (British Academy Occasional Paper 9). Oxford: Oxford University Press, 2007, p. 15-31. The transition to late Antiquity. In: SCHEIDEL, Walter; MORRIS, Ian; SALLER, Richard (org.). The Cambridge economic history of the Greco-Roman world. Cambridge: Cambridge University Press, 2007, p. 743-768.

GOFFART, Walter. Barbarians and Romans A. D. 418-584: The techniques of accommodation. Princeton: Princeton University Press, 1980. 
GREY, Cam. Contextualizing Colonatus: the Origo of the late Roman Empire. Journal of Roman Studies. Londres, n. 97, 2007, p. 155-175.

GUARINELLO, Norberto. Uma morfologia da história: As formas da história antiga. Politeia: História e Sociedade. Vitória da Conquista, 2003, v. 3, p. 41-61.

GWYNN, D. (org.). A. H. M. Jones and the later Roman Empire. Leiden: Brill, 2008.

HALDON, John. Social transformation in the 6th-9th c. East. In: BOWDEN, Will; GUTTERIDGE, Adam; MACHADO, Carlos (org.). Social and political life in late Antiquity (Late Antique archaeology 3.1). Leiden: Brill, 2006, p. 603-647.

HALSALL, Guy. The Barbarian invasions. In: FOURACRE, Paul (org.). The new Cambridge Medieval history, vol. 1, c. 500-c. 700. Cambridge: Cambridge University Press, 2005, p. 35-55.

HALSALL, Guy. Barbarian migrations and the Roman West, 376-568. Cambridge: Cambridge University Press, 2007.

HEATHER, Peter. The fall of the Roman Empire. Londres: MacMillan, 2005.

Why did the barbarians cross the Rhine?. Journal of Late Antiquity. Baltimore, n. 2, 2009, p. 3-29.

JONES, A. H. M. The later Roman Empire 284-602. A social, economic, and administrative survey, 3 vols. Oxford: Basil Blackwell, 1964.

JONES, Sian. The archaeology of ethnicity. Londres: Routledge, 1997.

KELLY, Christopher. Ruling the later Roman Empire. Cambridge, MA: Harvard University Press, 2004.

LANIADO, Avshalon. Recherches sur les notables municipaux dans l'empire protobyzantin. Paris: Centre d'Histoire et Civilisation de Byzance, 2002.

LAVAN, Luke. Christianity, the city and the end of Antiquity. Journal of Roman Archaeology. Portsmouth, n. 16, 2003, p. 705-710.

Fora and agorai in Mediterranean cities during the 4 th and 5th c. A. D. In: BOWDEN, Will; GUTTERIDGE, Adam; MACHADO, Carlos (org.). Social and political life in late Antiquity (Late antique archaeology 3.1). Leiden: Brill, 2006, p. 195-249.

A. H. M. Jones and "The cities", 1964-2004. In: GWYNN, David (org.). A. H. M. Jones and the later Roman Empire. Leiden: Brill, 2008, p. 167-192.

LEPELLEY, Claude. Les cités de l'Afrique romaine, vol. 1: La permanence d'une civilisation municipale. Paris: Études Augustiniennes, 1979.

La cité africaine tardive, de l'apogée du IVe siècle à l'effondrement du VII siècle. In: KRAUSE, Jens-Uwe $\mathcal{E}$ WITSCHEL, Christian (org.). Die Stadt in der Spätantike - Niedergang oder Wandel?. Stuttgart: Franz Steiner Verlag, 2006, p. 13-31.

LIEBESCHUETZ, Johann. H. W. G. Antioch: City and imperial administration in the later Roman Empire. Oxford: Oxford University Press, 1972.

The decline and fall of the Roman city. Oxford: Oxford University Press, 2001.

LIVERANI, Paolo. The Sunset of 3D. In: KRISTENSEN, Troels $\mathcal{E}$ STIRLING, Lea (org.). The afterlife of Roman sculpture: Late antique response and reception. Ann Arbor: The University of Michigan Press (no prelo). 
rev. hist. (São Paulo), n. 173, p. 81-114, jul.-dez., 2015 http://dx.doi.org/10.11606/issn.2316-9141.rh.2015.105844
Carlos Augusto Ribeiro Machado

A Antiguidade tardia, a queda do Império romano e o debate sobre o "fim do mundo antigo"

MAAS, Michael. John Lydus and the Roman past. Londres: Routledge, 1992.

MACHADO, Carlos. Building the past: Monuments and memory in the Forum Romanum. In: BOWDEN, Will; GUTTERIDGE, Adam; MACHADO, Carlos (org.). Social and political life in late Antiquity (Late antique archaeology 3.1). Leiden: Brill, 2006, p. 157-192.

Public monuments and civic life: The end of the statue habit in Italy. In: DELOGU, Paolo \& GASPARRI, Stefano (org.). Le trasformazioni del $V$ secolo. L'Italia, i barbari e l'Occidente romano. Turnhout: Brepols, 2010, p. 237-257.

MACMULLEN, Ramsay. Corruption and the decline of Rome. New Haven: Yale University Press, 1988.

MANACORDA, Daniele. Crypta Balbi. Archeologia e storia di un paesaggio urbano. Milão: Electa, 2001.

MARROU, Henri-Irenée. Saint Augustine et la fin de la culture antique. Paris: E. De Boccard, 1949. Seuil, 1977.

Décadence romaine ou Antiquité tardive? IIIe - VIe siècle. Paris: Éditions du

MAZZARINO, Santo. Stilicone: La crise imperiale dopo Teodosio. Milão: Rizzoli, 1942. . Aspetti sociali del quarto secolo: ricerche di storia tardo-romana. Roma: L'Erma di Bretschneider, 1951. . Antico, tardoantico ed èra costantiniana, 2 vols. Bari: Edizioni Dedalo, 1974. O fim do mundo antigo. São Paulo: Martins Fontes, 1988.

McLYNN, Neil. Ambrose of Milan: Church and court in a Christian capital. Berkeley: University of California Press, 1994.

MODÉRAN, Yves. La renaissance des cités dans l'Afrique du VIe siècle d'après une inscription récemment publiée. In: LEPELLEY, Claude (org.). La fin de la cité antique et le début de la cité médiévale. Bari: Edipuglia, 1996, p. 85-114.

MOMIGLIANO, Arnaldo. La caduta senza rumore di un Impero nel 476. In: Idem. Sesto contributo alla storia degli studi classici e del mondo antico. Roma: Edizioni di Storia e Letteratura, 1980, p. 159-165.

El cristianismo y la decadencia del Imperio romano. In: MOMIGLIANO, A. (org.). El conflicto entre el paganismo y el cristianismo en el siglo IV. Madri: Alianza Editorial, 1989, p. 15-30.

OLIVEIRA, Julio Cesar. Le "pouvoir du peuple": une émeute à Hippone au début du Ve siècle connue par le sermon 302 de saint Augustin pour la fête de saint Laurent. Antiquité Tardive. Turnhout, n. 12, 2004, p. 309-324.

PETIT, Paul. Libanius et la vie municipale à Antioche au IVe siècle aprés J.-C. Paris: Presses Universitaires de France, 1955.

PIGANIOL, André. L'empire chrétien. Paris: Presses Universitaires de France, 1947.

POHL, Walter. Romans and the Barbarians in the fifth century. Antiquité Tardive. Turnhout, n. 16, 2008, p. 93-100.

PRINGLE, Denys. Two fortified sites in Byzantine Africa: Aïn Djelloula and Henchir Sguidan. Antiquité Tardive. Turnhout, n. 10, 2002, p. 269-290. 
rev. hist. (São Paulo), n. 173, p. 81-114, jul.-dez., 2015 http://dx.doi.org/10.11606/issn.2316-9141.rh.2015.105844
Carlos Augusto Ribeiro Machado

A Antiguidade tardia, a queda do Império romano e o debate sobre o "fim do mundo antigo"

RANDSBORG, Klavs. Barbarians, classical Antiquity, and the rise of Western Europe: An archaeological essay. Past and Present. Oxford, n. 137, 1991, p. 8-24.

The first millenium A. D. in Europe and the Mediterranean: An archaeological essay. Cambridge: Cambridge University Press, 1991.

REBENICH, Stephen. Christian asceticism and Barbarian incursion: The making of a Christian catastrophe. Journal of Late Antiquity. Baltimore, n. 2, 2009, p. 49-59.

SILVA, Erica. Conflito politico-cultural na Antiguidade tardia: O "levante das estátuas" em Antioquia de Orontes (387 d. C.). Tese de doutoramento, Unesp, Franca, 2012.

SILVA, Gilvan Ventura da. Reis, santos e feiticeiros. Constâncio II e os fundamentos místicos da Basileia, 337-361. Vitória: Edufes, 2003.

SILVA, Uiran G. Bagaudas e circunceliões: revoltas rurais e a escrita da história das classes subalternas na Antiguidade tardia. Tese de doutoramento, USP, São Paulo, 2013.

SMITH, Roland. R. R. Late antique portraits in a public context: Honorific statuary at Aphrodisias in Caria, A. D. 300-600. Journal of Roman Studies. Londres, n. 89, 1999, p. 155-189.

Statue life in the Hadrianic baths at Aphrodisias, A. D. 100-600: Local context and historical meaning. In: BAUER, Franz Alto \& WITSCHEL, Christian (org.). Statuen in der Spätantike. Wiesbaden: Reichert Verlag, 2007, p. 203-235.

SMITH, Roland. R. R. \& RATTÉ, Christopher. Archaeological research at Aphrodisias in Caria, 1994. American Journal of Archaeology. Boston, n. 100, 1996, p. 5-33.

SMITH, Roland. R. R. \& WARD-PERKINS, Bryan. (org.). The last statues of Antiquity. Oxford: Oxford University Press (no prelo).

VALENTINI, Roberto $\mathcal{E}$ ZUCCHETTI, Giuseppe (org.). Codice topografico della città di Roma, vol. 1. Roma: Tipografia del Senato, 1940.

VAN OSSEL, Paul. Rural impoverishment in northern Gaul at the end of Antiquity: the contribution of archaeology. In: BOWDEN, Will; GUTTERIDGE, Adam; MACHADO, Carlos (org.). Social and political life in late Antiquity (Late antique archaeology 3.1). Leiden: Brill, 2006, p. 533-565.

VON RUMMEL, Philipp. The archaeology of 5th century Barbarians in north Africa. In: DELOGU, Paolo \& GASPARRI, Stefano (org.). Le trasformazioni del $V$ secolo. L'Italia, i barbari e l'Occidente romano. Turnhout: Brepols, 2010, p. 157-181.

WARD-PERKINS, Bryan. From classical Antiquity to the early Middle Ages. Urban public building in norther and central Italy, A. D. 300-800. Oxford: Oxford University Press, 1984.

Continuists, catastrophists, and the towns of post-Roman northern Italy. Papers of the British School at Rome. Londres, n. 65, 1997, p. 157-176.

The cities. In GARNSEY, Peter \& CAMERON, Averil (org.). The Cambridge ancient history, vol. XIII: The late Empire, A. D. 337-425. Cambridge: Cambridge University Press, 1998, p. 371-410.

Specialized production and exchange. In: CAMERON, Averil; WARD-PERKINS, Bryan; WHITBY, Michael (org.). The Cambridge ancient history, v. 14: Late Antiquity and its successors, A. D. 420-600. Cambridge: Cambridge University Press, 2000, p. 346-391.

. The fall of Rome and the end of civilization. Oxford: Oxford University Press, 2005. 
WHITEHOUSE, David \& HODGES, Richard. Mohammed, Charlemagne and the origins of Europe. Ithaca: Cornell University Press, 1983.

WHITTOW, Mark. The making of orthodox Byzantium, 600-1025. Basingstoke: Palgrave, 1996.

. Decline and fall? Studying long term change in the East. In: LAVAN, Luke $\mathcal{E}$ BOWDEN, Will (org.). Theory and practice in late antique archaeology (Late antique archaeology 1). Leiden: Brill, 2003, p. 404-423.

WICKHAM, Chris. The other transition: From the ancient world to feudalism. Past and Present. Londres, n. 103, 1984, p. 3-36.

. Framing the early Middle Ages. Europe and the Mediterranean, 400-800. Oxford: Oxford University Press, 2005.

.Theinheritance of Rome. A history of Europefrom 400 to 1000.Londres:Penguin, 2010.

WITSCHEL, Christian. Re-evaluating the Roman West in the $3^{\text {rd }}$ century. Journal of Roman Archaeology. Portsmouth, n. 17, 2004, p. 251-281.

WOOLF, Greg. Becoming Roman. The origins of provincial civilization in Gaul. Cambridge: Cambridge University Press, 1998.

WOOLF, Greg. Tales of the Barbarians. Oxford: Blackwell, 2011.

Recebido: 25/02/2015 - Aprovado: 25/08/2015 